\title{
Heterogeneity in rent-seeking contests with multiple stages: Theory and experimental evidence
}

Tanja Hörtnagl, Rudolf Kerschbamer, Rudi Stracke, Uwe Sunde

Working Papers in Economics and Statistics

2013-29 


\section{University of Innsbruck \\ Working Papers in Economics and Statistics}

The series is jointly edited and published by

- Department of Economics

- Department of Public Finance

- Department of Statistics

Contact Address:

University of Innsbruck

Department of Public Finance

Universitaetsstrasse 15

A-6020 Innsbruck

Austria

Tel: $\quad$ + 435125077171

Fax: $\quad+435125072970$

E-mail: eeecon@uibk.ac.at

The most recent version of all working papers can be downloaded at http://eeecon.uibk.ac.at/wopec/

For a list of recent papers see the backpages of this paper. 


\title{
Heterogeneity in Rent-Seeking Contests with Multiple Stages: Theory and Experimental Evidence*
}

\author{
Tanja Hörtnagl ${ }^{\mathrm{a}}$, Rudolf Kerschbamer ${ }^{\mathrm{a}}$, Rudi Stracke ${ }^{\mathrm{b}}$, and Uwe Sunde ${ }^{\mathrm{b}}$ \\ aDepartment of Economics, University of Innsbruck \\ ${ }^{\mathrm{b}}$ Seminar for Population Economics, University of Munich (LMU)
}

October 9, 2013

\begin{abstract}
This paper investigates how heterogeneity in contestants' investment costs affects the competition intensity in a dynamic elimination contest. Theory predicts that the absolute level of investment costs has no effect on the competition intensity in homogeneous interactions. Relative cost differences in heterogeneous interactions, however, reduce equilibrium expenditures. Evidence from lab experiments for treatments with homogeneous participants is qualitatively in line with the theoretical prediction. The effect of cost differences on expenditures is positive rather than negative, however, in all heterogeneous treatments.
\end{abstract}

JEL-Classification: C72, D72

Keywords: Multi-Stage Contest, Heterogeneity, Experiment, Joy of Winning

${ }^{*}$ Corresponding author: Rudi Stracke, Schackstr. 4, 80539 München (Germany); Tel.:+49-89-2180 1285; Fax:+49-89-2180 17834; Email: Rudi.Stracke@econ.lmu.de 


\section{Introduction}

Rent seeking contests are interactive decision situations in which several agents compete by expending valuable resources to receive some rent. Depending on the context, the rent might be a particular regulation or law that is implemented by policy makers due to lobbying of interest groups, an office awarded to the winner of a political campaign, a procurement contract that is profitable to the winning firm, or a patent which allows the winner of an R\&D contest to charge monopoly prices. Contest theory is not only used as an instrument to study the competition for a rent in public economics, however. Important application in other fields include bonus or promotion tournaments in labor economics, the organization of leagues in sports economics, and military conflicts in political sciences. Even though the same technical tools are used to study strategic behavior in all these settings, the measures which matter for an evaluation of the outcome are sometimes different: Labor economists are often interested in the efficiency of the tournament contract, for example, while sports economics mainly care about competitive balance. A common measure of interest in public economics is the rent-dissipation rate which normalizes aggregate expenditures by all contestants with the value of the rent at stake. The rent dissipation is not only directly related to the competition intensity in a contest, it also reveals the surplus that remains in settings where the rent is taken as given (rather than endogenously generated) after expenditures are accounted for.

An important finding in theoretical and empirical studies investigating static settings where contestants interact only once is that heterogeneity between rent seekers reduces the rent-dissipation rate. This is taken as an indication that the competition is less intense if contestants are heterogeneous rather than homogeneous. Even though many real-life applications can best be modelled as a dynamic multi-stage contest with heterogeneous participants - think of the presidential election in the U.S. where candidates must succeed in the primaries to qualify for the federal election, or of procurement contracts that involve a qualification stage, for example - we know of no study that theoretically or empirically analyzes the effect of heterogeneity on competition intensity in dynamic settings.

In this paper, we investigate theoretically and experimentally how heterogeneity in contestants' investment costs affects the competition intensity in a dynamic elimination contest. The theoretical analysis proceeds in two steps. First, we show that the absolute level of investment costs has no effect on the rent-dissipation rate in a two-stage version of the standard Tullock (1980) lottery contest with four homogeneous contestants: While contestants reduce their equilibrium investments as marginal investment costs increase, equilibrium expenditures and expected payoffs from contest participation remain constant. Second, we address our main research question by analyzing the effect of relative cost differences between compet- 
ing contestants on behavior in the same theoretical framework. In particular, we investigate how heterogeneity in different stages of the contest affects the aggregate rent-dissipation rate. To address this issue, we consider a setting with two low-cost and two high-cost contestants that allows for two different seeding variants: While equal types compete in stage-1 of setting LLHH, contestants are seeded such that different types interact in stage 1 of setting LHLH. An implication is that the stage-2 interaction is always between different types in setting LLHH, while equal types interact with high probability in stage 2 of setting LHLH. Thus, heterogeneity is basically shifted across stages in these two settings with heterogeneous contestants. In the theoretical investigation, we find that the rent-dissipation rate is lower in both heterogeneous settings than in any setting with homogeneous contestants. Moreover, a comparison of rent-dissipation rates across the two heterogeneous settings by stage indicates that heterogeneity has a negative impact on the competition intensity in any stage. Consequently, the stage-1 rent-dissipation rate is higher in setting LLHH than in LHLH, while the reverse relation holds for the stage-2 dissipation rate.

In the second part of the paper, we use lab experiments to test these theoretical predictions. We implement four treatments that differ only with respect to the investment cost parameters of contestants. In addition to the heterogeneous treatments LLHH and LHLH where contestants of both types interact with each other, we implement the two homogeneous treatments LLLL and HHHH where all contestants have low or high investment costs, respectively. While we observe high degrees of over-dissipation relative to the benchmark prediction in all treatments, the experimental data show that the aggregate rent-dissipation rate in the two homogeneous treatments is almost exactly the same. This does still hold if we disaggregate the data and separately compare the stage- 1 and stage- 2 rent-dissipation rates across treatments. Thus, the experimental evidence is in line with the qualitative prediction that the level of investment costs has no effect on the rent-dissipation rate if contestants are homogeneous. The effect of heterogeneity on the rent-dissipation rate goes counter to theoretical prediction, however. Specifically, we observe that the rent-dissipation rate is higher - and not lower in the heterogeneous treatments LLHH and LHLH than in the homogeneous treatments LLLL and HHHH. When disaggregating the data by stage, we find that heterogeneity in stage 2 has almost no effect on rent dissipation in this stage, while the effect of heterogeneity is strictly positive in stage 1. Additional analyses of the experimental data suggests that confusion, which might arise due to the strategic complexity of a dynamic contest, is unlikely to be the main explanation for these findings. Instead, it seems that behavioral factors such as 'joy of winning' and 'joy of competing' are responsible for the pattern we observe.

Our results suggest that behavior in the qualification stage of a multi-stage contest strongly deviates even from qualitative predictions of a model that assumes rational and 
risk-neutral agents. While this is already suggested by existing studies investigating behavior in homogeneous contests, we show that this effect is even more pronounced when contestants are heterogeneous - heterogeneity seems to strengthen the behavioral effects that were previously shown to be particularly important in the initial stage of a competition with multiple stages. An important consequence is that heterogeneity in the qualification stage increases the competition intensity in dynamic settings, in contrast to what is commonly observed in static contests and what theoretical models predict.

This paper contributes to the extensive theoretical and to the growing experimental literature on multi-stage contests. Such contests were first proposed by Rosen (1986) to model dynamic promotion tournaments in labor markets. Even though this paper already discusses settings with heterogeneous contestants, it focusses on the optimal structure of rewards without analyzing the effect of heterogeneity on competition intensity. Subsequent theoretical work on dynamic contests also addresses different issues: Gradstein and Konrad (1999) and $\mathrm{Fu}$ and $\mathrm{Lu}$ (2013) are both concerned with the effect of repeated interactions in dynamic contests on investment decisions, but they restrict attention to settings with homogeneous agents. While Harbaugh and Klumpp (2005) allow for heterogeneity, they investigate how binding budget constraints affect optimal behavior in different stages of a dynamic contest.1 Stein and Rapoport (2004) and Stracke (2013) compare different contest structures with heterogeneous participants with each other, but not with a homogeneous benchmark. The same holds for the literature on the optimal seeding of heterogeneous agents which does not vary the structure of the competition, but rather the allocation of the same set of players across different interactions - see Groh, Moldovanu, Sela, and Sunde (2012), Höchtl, Kerschbamer, Stracke, and Sunde (2011), and Kräkel (2013).

The experimental literature has only recently started to investigate behavior in contests with multiple stages. Our experimental setup is similar to the one used by Sheremeta (2010b) and Altmann, Falk, and Wibral (2012). In line with what they report, we find that experimental subjects invest too much in stage 1 of the contest. However, both of these studies restrict attention to settings with homogeneous contestants and compare static one-stage with dynamic two-stage elimination contests, while we focus on the effect of heterogeneity on competition intensity. Previous studies by Parco, Rapoport, and Amaldoss (2005) and Amegashie, Cadsby, and Song (2007) also observe relative over-dissipation in stage 1 of a two-stage contest, but their results are less relevant for the qualification of our findings since they assume that agents are budget constrained. Other less related experimental studies on multi-stage contests allow for effort carryover across stages (Sheremeta 2010a) or analyze the optimal structure of prizes, assuming that contestants are homogeneous (Stracke, Höchtl,

\footnotetext{
${ }^{1}$ See Stein and Rapoport (2005) for a related study that assumes homogeneity of contestants.
} 
Kerschbamer, and Sunde 2012). Settings with heterogeneous agents have only been considered for static contests. The seminal contribution is by Bull, Schotter, and Weigelt (1987), subsequent studies incluce Anderson and Stafford (2003), Schotter and Weigelt (1992), and Kimbrough, Sheremeta, and Shields (2011), for example.2 These studies share the finding that heterogeneity between contestants reduces competition intensity in static contests, while we find the opposite for dynamic contests.

The remainder of this paper is organized as follows: Section 2 analyzes the effects of variations in the level of investment costs and of cost-heterogeneity on the rent-dissipation rate in a simple dynamic contest model; moreover, the robustness of our theoretical findings is briefly discussed. Section 3 outlines the experimental design and derives our main hypotheses. The experimental results are presented and discussed in Section 4, and Section 5 concludes.

\section{Theoretical Analysis}

\subsection{A Dynamic Contest with Heterogeneous Contestants}

Consider the simplest version of a dynamic pairwise elimination contest with two stages, as depicted in Figure 1. Each of the three pairwise interactions is modelled as a Tullock (1980) lottery contest with linear investment costs. The four risk-neutral contestants who compete for the indivisible rent $R$ are of two different types. In particular, each unit invested into the contest $\operatorname{costs} c_{\mathrm{L}}$ for low-cost contestants, while constant marginal investment costs for the high-cost contestants amount to $c_{\mathrm{H}}>c_{\mathrm{L}}$; types and thus investment cost parameters are common knowledge among contestants.

We consider two homogeneous and two heterogeneous versions of the model. In each homogeneous contest, the investment cost parameter is the same for all participants; in LLLL it is low for all, while the cost parameter is high for all participants in HHHH. In heterogeneous versions of the model, we assume that equal shares of the two types participate in the contest. This allows for two strategically different seeding variants with heterogeneous participants: Contestants can either be seeded to ensure that equal types interact in stage 1 (LLHH), or in such a way that both stage- 1 interactions are heterogeneous (LHLH). The relevant equilibrium concept is Subgame Perfect Nash in all cases. Thus, we solve the game via backwards induction and consider the stage-2 subgame before we determine equilibrium behavior in stage 1.

\footnotetext{
${ }^{2}$ See Dechenaux, Kovenock, and Sheremeta (2012) for a recent survey of the experimental contest literature.
} 


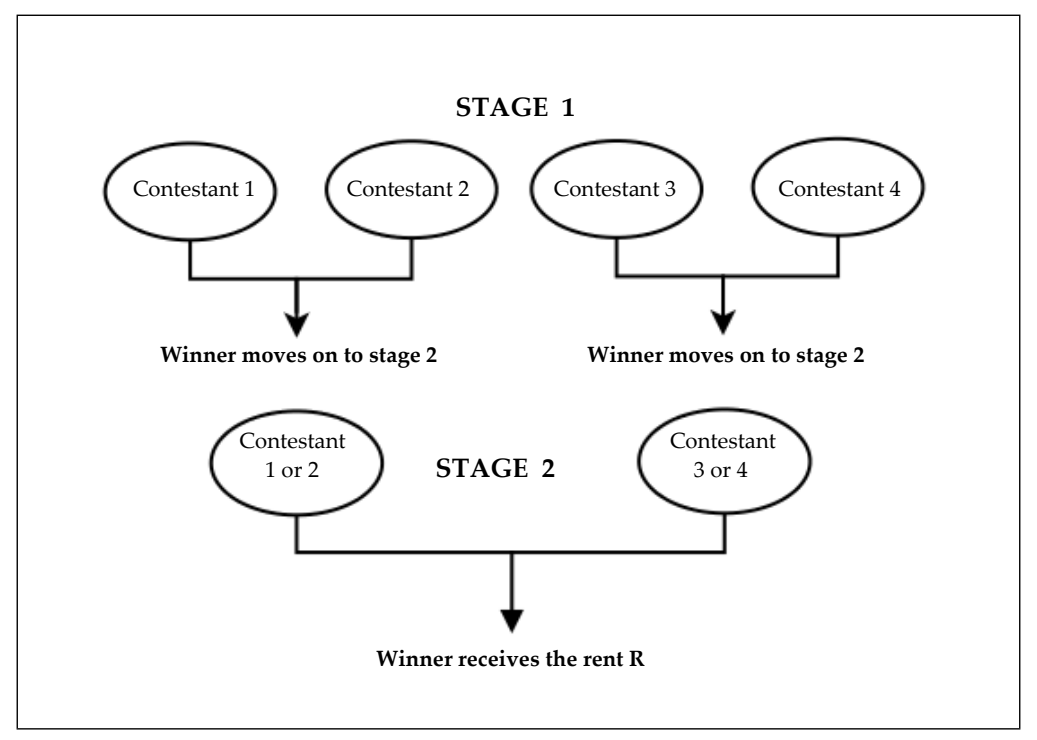

Figure 1: Structure of the Contest

\subsubsection{Solving Stage 2}

The stage- 2 subgame is a pairwise interaction between two contestants $i$ and $j$ with investment $\operatorname{costs} c_{i}$ and $c_{j}$, respectively. Each contestant chooses her investment level to maximize the expected payoff. Contest investment increases the probability to receive the indivisible rent $R$, but leads to investment costs that are independent of success or failure. The formal optimization problem of contestant $i$ reads

$$
\max _{x_{2 i} \geq 0} \Pi_{2 i}\left(x_{2 i}, x_{j}\right)=\frac{x_{2 i}}{x_{2 i}+x_{2 j}} R-c_{i} x_{2 i}
$$

where $x_{2 i}\left(x_{2 j}\right)$ denotes contest investment by $i(j)$ in stage 2. Following Nti (1999), first-order optimality conditions determine the unique pure strategy Nash equilibrium. Equilibrium investments satisfy

$$
x_{2 i}^{*}=\frac{c_{j}}{\left(c_{i}+c_{j}\right)^{2}} R ; \quad x_{2 j}^{*}=\frac{c_{i}}{\left(c_{i}+c_{j}\right)^{2}} R .
$$

Inserting equilibrium investments in the objective functions delivers

$$
\Pi_{2 i}^{*} \equiv \Pi_{2 i}\left(x_{2 i}^{*}, x_{2 j}^{*}\right)=\frac{c_{j}^{2}}{\left(c_{i}+c_{j}\right)^{2}} R ; \quad \Pi_{2 j}^{*} \equiv \Pi_{2 j}\left(x_{2 j}^{*}, x_{2 i}^{*}\right)=\frac{c_{i}^{2}}{\left(c_{i}+c_{j}\right)^{2}} R
$$

Expected equilibrium payoffs from a participation in the last stage of the contest are stricly positive, decreasing in the own cost parameter, and increasing in the cost parameter of the opponent. 


\subsubsection{Solving Stage 1}

Since there is no immediate reward for winning in stage 1 , contestants only compete for the continuation value, that is, for the right to participate in stage 2 . This value is determined by the expected stage-2 equilibrium payoff in (2), as discussed in detail below. First, however, consider the stage-1 optimization problem of some contestant $i$ with investment $\operatorname{costs} c_{i}$ who competes with contestant $j$ for a given continuation value $C V_{i}$. The problem is formally defined as follows:

$$
\max _{x_{1 i} \geq 0} \Pi_{1 i}\left(x_{1 i}, x_{1 j}\right)=\frac{x_{1 i}}{x_{1 i}+x_{1 j}} C V_{i}-c_{i} x_{1 i}
$$

where $x_{1 i}\left(x_{1 j}\right)$ is the stage- 1 investment level of contestant $i(j)$. Stage-1 equilibrium investment choices by contestants $i$ and $j$ for given continuation values $C V_{i}$ and $C V_{j}$ read

$$
x_{1 i}^{*}=\frac{c_{j} C V_{i} C V_{j}}{\left(c_{i} C V_{j}+c_{j} C V_{i}\right)^{2}} C V_{i} ; \quad x_{1 j}^{*}=\frac{c_{i} C V_{j} C V_{i}}{\left(c_{i} C V_{j}+c_{j} C V_{i}\right)^{2}} C V_{j} .
$$

In the next step, we formally derive the continuation values for the four settings.

Settings LLLL and HHHH: In case of homogeneity, the continuation value is the same for all contestants and it is independent of the level of unit costs in the unique equilibrium which is symmetric $]^{3}$ Given $c_{i}=c_{j}$, it follows from (2) that the continuation value reads

$$
C V=\frac{1}{4} R
$$

Setting LLHH: If contestants are heterogeneous and seeded in such a way that equal types interact in stage 1, one high-cost and one low-cost contestant will make it to stage 2, independent of the outcomes in the two stage- 1 interactions. Thus, contestants know which type they will face in stage 2 if they win in stage 1 . In particular, any low-cost contestant in the stage-1 competition anticipates that she will meet a high-cost opponent in stage 2 , and vice versa. Thus, it follows from (2) that the continuation values read

$$
C V_{\mathrm{L}}=\frac{c_{\mathrm{H}}^{2}}{\left(c_{\mathrm{L}}+c_{\mathrm{H}}\right)^{2}} R \quad \text { and } \quad C V_{\mathrm{H}}=\frac{c_{\mathrm{L}}^{2}}{\left(c_{\mathrm{L}}+c_{\mathrm{H}}\right)^{2}} R
$$

for a low-cost and a high cost contestant, respectively. Intuitively, the continuation value of each contestant is independent of the outcome in the parallel stage- 1 interaction, since only the type (and not the identity) of the stage-2 opponent matters for the expected equilibrium payoff.

\footnotetext{
${ }^{3}$ Asymmetric equilibria do not exist in a lottery contest - see Cornes and Hartley (2005) for details.
} 
Setting LHLH: If heterogenenous contestants are seeded such that different types interact in stage 1 , contestants do not know the type of opponent they would face in stage 2 in case of success when competing in stage 1 since either of the two types from the other semifinal makes it to the final with a positive and endogenously determined probability. This complicates continuation values, since the value of participation in the final depends on the expected type of the opponent. To illustrate this argument, consider the stage- 1 interaction between a low-cost and a high-cost contestant with continuation values $C V_{\mathrm{L}}$ and $C V_{\mathrm{H}}$, respectively. These values are formally defined as

$$
C V_{\mathrm{L}}=q_{\mathrm{L}} \cdot \frac{R}{4}+\left(1-q_{\mathrm{L}}\right) \cdot \frac{c_{\mathrm{H}}^{2}}{\left(c_{\mathrm{L}}+c_{\mathrm{H}}\right)^{2}} R ; \quad C V_{\mathrm{H}}=q_{\mathrm{L}} \cdot \frac{c_{\mathrm{L}}^{2}}{\left(c_{\mathrm{L}}+c_{\mathrm{H}}\right)^{2}} R+\left(1-q_{\mathrm{L}}\right) \cdot \frac{R}{4},
$$

where $q_{\mathrm{L}}$, the probability that the second low-cost contestants wins, is endogenously determined by contest investments in the parallel stage-1 interaction. Since the continuation values in the parallel stage- 1 interaction have the same structure, stage- 1 investment choices by all four contestants are interdependent through endogenously determined continuation values. It can be shown, however, that the probability of a low-cost contestants to win in stage 1 is the same in both stage-1 interactions in the unique equilibrium. This symmetry allows to determine the equilibrium stage- 1 winning probability of a low-cost contestant, $q_{\mathrm{L}}^{*}$. It reads ${ }^{4}$

$$
q_{\mathrm{L}}^{*}=\frac{\left(c_{\mathrm{H}}-c_{\mathrm{L}}\right)\left(c_{\mathrm{H}}+c_{\mathrm{S}}\right)^{2}+\sqrt{64 c_{\mathrm{H}}^{3} c_{\mathrm{L}}^{3}+\left(c_{\mathrm{L}}-c_{\mathrm{H}}\right)^{2}\left(c_{\mathrm{L}}+c_{\mathrm{H}}\right)^{4}}}{\left(c_{\mathrm{H}}-c_{\mathrm{L}}\right)\left(c_{\mathrm{H}}+c_{\mathrm{L}}\right)^{2}+\sqrt{64 c_{\mathrm{H}}^{3} c_{\mathrm{L}}^{3}+\left(c_{\mathrm{L}}-c_{\mathrm{H}}\right)^{2}\left(c_{\mathrm{L}}+c_{\mathrm{H}}\right)^{4}}+8 c_{\mathrm{L}}^{3}} .
$$

\subsection{Rent Dissipation Rates and Heterogeneity}

A common measure for the intensity of a rent-seeking contest is the rent-dissipation rate, defined as the share of the contested rent that is invested into the contest. Let $\mathrm{DR}_{s}$, the rent-dissipation rate in stage $s \in\{1,2\}$, be defined as the ratio of aggregate expenditures $\operatorname{EXP}_{s}$ of all contestants in that stage over the rent $R$. Then, the aggregate rent-dissipation rate in setting $\mathrm{T} \in\{$ LLLL , HHHH, LLHH, LHLH $\}$ across both stages of the contest reads

$$
\mathrm{DR}(\mathrm{T})=\sum_{s} \mathrm{DR}_{s}(\mathrm{~T})=\sum_{s} \frac{\operatorname{EXP}_{s}(\mathrm{~T})}{R}
$$

Since DR(T) relates total expenditures by rent-seekers to the value of the rent at stake, it is closely related to average gains for rent-seekers. In particular, expected average gains are decreasing in the rent-dissipation rate, such that this measure reveals the attractiveness to enter a rent-seeking contest.

An important advantage of the rent-dissipation rate over other measures of contest in-

\footnotetext{
${ }^{4}$ Details are provided in Appendix A.
} 
tensity (e.g. total investment) is that it does not depend on the level of the cost parameter in homogeneous settings. In particular, the rent-dissipation rate in a dynamic contest with four low-cost contestants (LLLL) is the same as in a model with four high-cost contestants ( $\mathrm{HHHH})$.

Proposition 1 (Homogeneity). Aggregate rent dissipation across both stages, as well as rent dissipation in each stage do not depend on the level of the cost parameter in homogeneous settings. That is,
(a) $\mathrm{DR}(\mathrm{LLLL})=\mathrm{DR}(\mathrm{HHHH}) \equiv \mathrm{DR}(\mathrm{HOM})$
(b) $\mathrm{DR}_{1}(\mathrm{LLLL})=\mathrm{DR}_{1}(\mathrm{HHHH}) \equiv \mathrm{DR}_{1}(\mathrm{HOM})$
(c) $\mathrm{DR}_{2}(\mathrm{LLLL})=\mathrm{DR}_{2}(\mathrm{HHHH}) \equiv \mathrm{DR}_{2}(\mathrm{HOM})$

Proof. See Appendix B.

Proposition 1 will help to address the main research question of our analysis, namely how heterogeneity between contestants affects aggregate rent dissipation across both stages of the contest and thus the attractiveness to enter a rent-seeking competition.

While it is a well established result for static contests that rent dissipation is lower in heterogeneous than in homogeneous interactions, dynamic elimination structures with heterogeneous contestants and multiple sequential interactions have not been analyzed yet. To address this issue, we compare the aggregate rent-dissipation rate in HOMto the rates in LLHH and LHLH. These comparisons yield:

Proposition 2 (Aggregate Effect of Heterogeneity). Aggregate rent dissipation across both stages is lower if contestants are heterogeneous than if they are homogeneous. That is,
(a) $\mathrm{DR}(\mathrm{HOM})>\mathrm{DR}(\mathrm{LLHH})$;
(b) $\mathrm{DR}(\mathrm{HOM})>\mathrm{DR}(\mathrm{LHLH})$.

Proof. See Appendix B.

According to this finding, the result established for static models that rent dissipation is lower in heterogeneous than in homogeneous interactions carries over to dynamic structures.

Note that heterogeneity is basically shifted across stages when moving from LLHH to LHLH: The two stage-1 interactions are homogeneous in setting LLHH, while different types interact in stage 1 of setting LHLH. At the same time, the stage- 2 interaction is always heterogeneous in LLHH and often homogeneous in LHLH. Thus, a comparison of stage-specific rent-dissipation rates across settings LLHH and LHLH allows us to analyze the effect of heterogeneity on the 
rent-dissipation rate in different stages of the contest. In line with standard intuition, we find that the rent-dissipation rate in a particular stage is lower in heterogeneous than in homogeneous interactions.

Proposition 3 (Stage Effect of Heterogeneity). Rent dissipation in a particular stage is higher if interactions in that stage are between homogeneous rather than heterogeneous types. That is,
(a) $\mathrm{DR}_{1}(\mathrm{LHLH})<\mathrm{DR}_{1}(\mathrm{LLHH})$
(b) $\mathrm{DR}_{2}(\mathrm{LHLH})>\mathrm{DR}_{2}(\mathrm{LLHH})$.

Proof. See Appendix B.

The previous proposition suggests that the seeding of types in stage 1 shifts expenditures across stages: While the stage-1 rent-dissipation rate is higher in LLHH than in LHLH, the reverse relation holds for rent dissipation in stage 2 .

\subsection{Discussion and Robustness}

Even though the dynamic contest structure we consider has already received some attention, the aggregate effect of heterogeneity in a dynamic contest has not yet been analyzed to the best of our knowledge. The existing literature either assumes homogeneity, or considers a more general framework with more than two types. Even in the latter case, the issue of how heterogeneity affects behavior is not addressed explicitly, since the degree of heterogeneity is hard to define if there are more than two types. In a two-stage model with four types, for example, there is some heterogeneity between all players, but it is not clear whether heterogeneity increases or decreases when the investment cost parameter of an intermediate type changes; that player becomes more similar to one and less similar to another competitor, then.

The issue how the seeding of types in stage 1 affects investment decisions by contestants received some attention already, however. Groh et al. (2013) prove that seeding LHLH maximizes aggregate investments in a perfectly discriminating contest where a marginal lead by any contestant leads to a sure win. Kräkel (2013) shows that the optimal seeding crucially depends on the relative importance of contest investment and noise for the outcome: Seeding LHLH maximizes aggregate investments when the outcome is almost entirely determined by relative investment choices, while seeding LLHH becomes optimal in this dimension if contest investments become less and chance more important for the probability of success. The Tullock lottery contest we consider is an example of the latter, i.e., aggregate contest investments 
are higher in setting LLHH than in LHLH in our model - see Höchtl, Kerschbamer, Stracke, and Sunde (2011) for details. While the contest technology determines the relative importance of investment choices in stage 1 and stage 2, respectively, for aggregate contest investments, it is always the case that investments are lower in an interaction with heterogeneous than in one with homogeneous types. Thus, Proposition 3 is robust to variations of the contest technology.

\section{Experimental Design and Procedures}

\subsection{Experimental Treatments and Testable Hypotheses}

Our experimental design involves four treatments that correspond to the four settings studied in the previous section, with investment cost parameters $c_{\mathrm{L}}$ and $c_{\mathrm{H}}$ set to 1 and 1.5, respectively, and the contested rent $R$ set to 240 . Table 1 shows the theoretical equilibrium predictions from the model in Section 2.1 for all treatments. The theoretically predicted aggregate rent-dissipation rates are always below one, such that the contested rent is never completely dissipated. Consequently, the expected payoff from a participation is strictly positive for contestants in all treatments, and the participation constraint is always satisfied.

In a first step, we compare rent-dissipation rates in the homogeneous treatments, which are predicted to be the same. This allows us to test the hypothesis:

Hypothesis 1 (Homogeneity). Aggregate rent dissipation across both stages of the contest, as well as rent dissipation in each stage are the same in treatments LLLL and HHHH:
(a) $\quad \mathrm{DR}(\mathrm{LLLL})=\mathrm{DR}(\mathrm{HHHH})$;
(b) $\quad \mathrm{DR}_{1}(\mathrm{LLLL})=\mathrm{DR}_{2}(\mathrm{HHHH})$;
(c) $\quad \mathrm{DR}_{2}(\mathrm{LLLL})=\mathrm{DR}_{2}(\mathrm{HHHH})$.

To test the hypothesis that heterogeneity reduces aggregate rent dissipation, we compare the rent-dissipation rates in homogeneous and heterogeneous treatments.

Hypothesis 2 (Aggregate Effect of Heterogeneity). Heterogeneity between contestants reduces aggregate rent dissipation across both stages of the contest:

$$
\begin{aligned}
& \text { (a) } \operatorname{Min}\{\mathrm{DR}(\mathrm{LLLL}), \mathrm{DR}(\mathrm{HHHH})\} \geq \mathrm{DR}(\mathrm{LLHH}) ; \\
& \text { (b) } \operatorname{Min}\{\mathrm{DR}(\mathrm{LLLL}), \mathrm{DR}(\mathrm{HHHH})\} \geq \mathrm{DR}(\mathrm{LHLH}) .
\end{aligned}
$$

The theoretical analysis and Table 1 not only suggest that heterogeneity reduces the rent- 
Table 1: Theoretical Predictions for Rent-Dissipation Rate

\begin{tabular}{lllllll}
\hline \hline & & \multicolumn{2}{c}{ Homogeneity } & & \multicolumn{2}{c}{ Heterogeneity } \\
\cline { 3 - 4 } \cline { 7 - 7 } & & LLLL & HHHH & & LLHH & LHLH \\
\hline Aggregate & $(\mathbf{D R})$ & 0.750 & 0.750 & & 0.738 & 0.683 \\
Stage-1 & $\left(\mathbf{D R}_{1}\right)$ & 0.250 & 0.250 & & 0.258 & 0.192 \\
Stage-2 & $\left(\mathbf{D R}_{2}\right)$ & 0.500 & 0.500 & & 0.479 & 0.491 \\
\hline \hline
\end{tabular}

Note: Number stands for predicted rent-dissipation rate in the respective treatment. Investment costs equal $c_{\mathrm{L}}=1$ and $c_{\mathrm{H}}=1.5$; the contested rent equals $R=240$.

dissipation rate, but also predict that the seeding of contestants has an effect on the competition intensity in each stage. In particular, the share of the rent that is dissipated in a particular stage is higher if the interaction(s) in that stage are likely to be between equal types:

Hypothesis 3 (Stage Effect of Heterogeneity). The stage-1 rent-dissipation rate is higher in LLHH than in LHLH, but the stage-2 rent-dissipation rate is higher in LHLH than in LLHH:
(a) $\mathrm{DR}_{1}(\mathrm{LHLH}) \leq \mathrm{DR}_{1}(\mathrm{LLHH})$
(b) $\quad \mathrm{DR}_{2}(\mathrm{LHLH}) \geq \mathrm{DR}_{2}(\mathrm{LLHH})$.

\subsection{Experimental Procedures}

Protocol of an Experimental Session. We adopt a between-subject design; that is, our experimental subjects encountered only one of the four treatments LLLL, LLHH, LHLH and HHHH. The protocol of an experimental session was the same for all treatments: First, participants received some general information about the experimental session. Then, instructions for the respective treatment (either LLLL, LLHH, LHLH or HHHH) were distributed 5 After each participant confirmed that he/she had read and understood the instructions, participants had to answer a set of control questions correctly. Subsequently, each subject was informed about her investment cost parameter. Only then did the first decision round start. Overall, each subject participated in 30 decision rounds and subjects were informed on that at the beginning. They were also informed that only four decision rounds (out of 30) would be randomly chosen and paid out at the end of the experiment. This was done in order to

\footnotetext{
${ }^{5} \mathrm{~A}$ translated version of the instructions is provided in Appendix C. The original (German) instructions are available from the authors upon request.
} 
minimize the potential impact of income effects. To minimize the potential impact of repeated game effects, subjects were randomly matched in each round and they were informed on that at the beginning. Matching groups corresponded to the entire session. After the main treatment, we first elicited risk preferences using a standard incentivized procedure, and then asked participants to fill out a questionnaire (voluntary and non-incentivized). Only thereafter participants were informed about their payoff in the experimental session. We ran a total of 18 computerized sessions (five for treatments LLLL, LLHH and LHLH; three for treatment $\mathrm{HHHH}$ ) with 20 participants per session. The experiment was programmed in $\mathrm{z}^{-}$ Tree (Fischbacher 2007), and we used experimental currency units (ECU) in all experimental sessions, where 200 ECU corresponded to 1.00 Euro. All 360 participants were students from the University of Innsbruck, which were recruited using ORSEE (Greiner 2004). Each session lasted approximately 70 minutes in total (including the distribution of instructions at the beginning and the payment at the end), and participants earned between 9 and 13 Euro (approximately 11 Euro on average) ${ }^{6}$

Implementation of the Contest. Participants played 30 rounds of the same contest game in all treatments. Each participant knew that the identities of her opponents were randomly determined at the start of each decision round, while the own investment cost parameter as well as those of the other contestants (and in particular that of the stage- 1 opponent) remained constant across decision rounds. Apart from the number of type-L/type-H subjects and their initial seeding in stage 1, everything else was kept constant across treatments. The role of investments into the contest was explained to subjects using a lottery analogy. Specifically, participants were told that they could buy a discrete number of balls in each interaction for the price $c_{\mathrm{L}}=1$ or $c_{\mathrm{H}}=1.5$, respectively.7 The balls purchased by the subjects as well as those purchased by their respective opponents were then said to be placed in the same ballot box, out of which one ball would be randomly drawn subsequently. This set-up replicates the Tullock (1980) lottery contest technology studied in the theoretical analysis. Players had to buy (and pay for) their desired number of balls before they knew whether or not they won a pairwise interaction in the contest. For this purpose, each participant received an endowment of 240 Taler in each round, independent of his/her type. This endowment could then be used to buy balls on both stages, i.e., a subject that reached stage 2 could use

\footnotetext{
${ }^{6}$ In six sessions an additional experiment was conducted after the risk-elicitation part. This experiment was entirely unrelated to the contest experiment and subjects were not informed about what to expect in this third experiment. All they knew is that the session included a third part, rather than only two parts. These sessions where approximately 15 minutes longer, and the earnings in this third part amounted to approximately 2.50 Euros on average.

${ }^{7}$ The chosen prizes ensure existence and uniqueness of equilibrium in each of the four treatments despite the discrete grid on the strategy space.
} 
Table 2: Main Results

\begin{tabular}{lcccccc}
\hline \hline & \multicolumn{2}{c}{ Homogeneity } & & \multicolumn{2}{c}{ Heterogeneity } \\
\cline { 2 - 3 } \cline { 6 - 6 } & LLLL & HHHH & & LLHH & LHLH \\
\hline \multirow{2}{*}{$\mathbf{D R}$} & $\mathbf{1 . 2 7 1}$ & $\mathbf{1 . 2 6 2}$ & & $\mathbf{1 . 4 2 7}$ & $\mathbf{1 . 5 2 6}$ \\
& $(0.750)$ & $(0.750)$ & & $(0.738)$ & $(0.683)$ \\
$\mathbf{D R}_{1}$ & $\mathbf{0 . 5 7 2}$ & $\mathbf{0 . 5 4 7}$ & & $\mathbf{0 . 6 7 9}$ & $\mathbf{0 . 8 1 5}$ \\
& $(0.250)$ & $(0.250)$ & & $(0.258)$ & $(0.192)$ \\
$\mathbf{D R}_{2}$ & $\mathbf{0 . 6 9 9}$ & $\mathbf{0 . 7 1 5}$ & & $\mathbf{0 . 7 4 8}$ & $\mathbf{0 . 7 1 1}$ \\
& $(0.500)$ & $(0.500)$ & & $(0.479)$ & $(0.491)$ \\
& & & & &
\end{tabular}

Note: Bold numbers denote rent-dissipation rate averages over all rounds of experimental sessions. DR is defined as average expenditures over both stages by subject, multiplied by four and divided by the value of the rent $R=240$. Theoretical benchmarks (from Table 1 are provided in parentheses below the respective measure.

whatever remained of his/her endowment to buy balls in the stage- 2 interaction. The part of the endowment that a participant did not use to buy balls was added to the payoffs for that round. Since the endowment was as high as the value of the rent $R$, agents were not budgetconstrained at any time 8 Experimental subjects were told that the endowment could only be used in a given round, that is, that transfers across decision rounds were not possible. Therefore, the strategic interaction is the same in each of the 30 decision rounds. After each decision round, participants were informed about their own decision, the decision(s) of their immediate opponent(s), and about their own payoff. This allows for an investigation of whether players learn when completing the task repeatedly.

\section{Experimental Results}

The main experimental results are summarized in Table 2. The table displays the theoretical predictions from the model in Section 2.1 as well as observed means for the aggregate, the stage- 1 and the stage- 2 rent-dissipation rate for the different treatments. The empirically observed rent-dissipation rates substantially exceed their theoretical counterparts in all treatments and in both stages. This is in line with the findings of other authors. For instance, the rent-dissipation rates we observe in the two homogeneous treatments LLLL and HHHH are well in line with Sheremeta (2010b) who reports even slightly higher degrees of over-dissipation in

\footnotetext{
${ }^{8}$ This is also confirmed by the experimental data on investment decisions.
} 
Figure 2: Rent-Dissipation in LLLL and HHHH by Decision Round and Stage

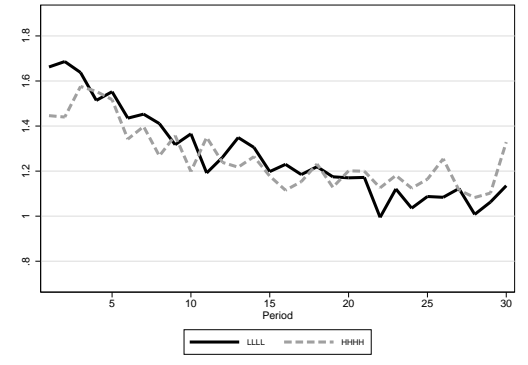

(a) Aggregate

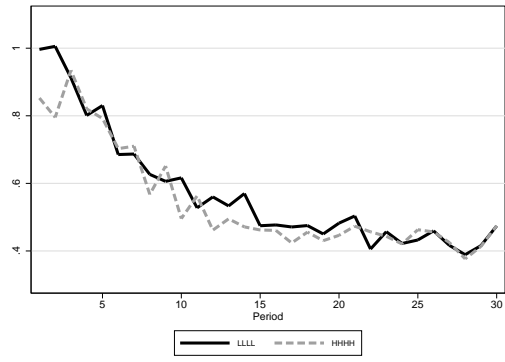

(b) Stage-1

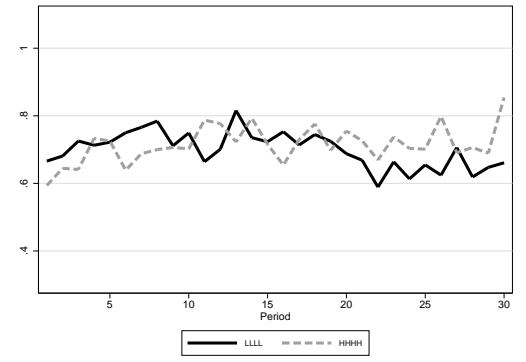

(c) Stage-2

an almost identical two-stage 'winner-takes-all' contest with four homogeneous contestants. 9 Given the high absolute differences between theoretical benchmarks and experimental results we follow the rest of the literature in focussing on qualitative rather than quantitative predictions in the subsequent analysis.

\subsection{Results Regarding the Hypotheses}

We proceed in the same order as in Subsection 3.1, starting with the comparison of rentdissipation rates across the two homogeneous treatments. According to the numbers in Table 2. observed means for aggregate, stage-1 and stage-2 rent-dissipation rates are remarkably similar across treatments LLLL and HHHH, in line with the theoretical prediction. A randomeffect panel regression of the respective dissipation measure on a treatment dummy indicates that we cannot reject any part of Hypothesis 1 - the respective p-values are 0.943 for the aggregate, 0.800 for the stage- 1 , and 0.859 for the stage-2 rent-dissipation rate ${ }^{10}$ Figure 2 plots aggregate, stage-1, and stage-2 dissipation rates in the two treatments separately for each decision round and show that the equality relation is not only reflected in session means. Dissipation rates are very similar in the homogeneous treatments in all decision rounds and follow the same time trend: The stage- 1 rent-dissipation rate is strongly decreasing in the first half of an experimental session in both treatments, while stage-2 dissipation rates remain rather constant. Consequently, the aggregate rent-dissipation rate is decreasing over the course of an experimental session, which indicates that subjects realize that their initial contest investments were too high. Dissipation rates exceed their theoretical counterparts even in the very last decision rounds, however. We summarize our findings with respect to the comparison of the homogeneous treatments as follows:

\footnotetext{
${ }^{9}$ Over-dissipation is not a particular feature of multi-stage contests, but can be observed in almost any contest experiment - see Sheremeta (2013) for an extensive survey and potential explanations of this behavior.

${ }^{10}$ Standard errors are clustered on the session level to account for potential interdependencies due to random matching within each session.
} 
Result 1 (Homogeneity). In line with the theoretical prediction, aggregate, stage-1, and stage2 rent-dissipation rates are remarkably similar across the homogeneous treatments LLLL and HHHH. Thus, we cannot reject Hypothesis 1 .

Hypothesis 2 is concerned with the effect of heterogeneity on rent dissipation. While the theoretical model predicts that heterogeneity between contestants reduces the aggregate rentdissipation rate, this is not what we observe in the experiments. On the contrary, observed means for DR equal 1.427 and 1.526 in the heterogeneous treatments LLHH and LHLH, respectively, compared to only 1.271 and 1.262 in the homogeneous treatments LLLL and HHHH. Since the difference between LLLL and HHHH is economically small and statistically insignificant, we will use LLLL as the homogeneous benchmark in the sequel. Based on this benchmark, the respective differences are large enough to reject Hypothesis 2(a) at the 10\%- (p-value 0.0595) and Hypothesis 2(b) at the 5\%-level (p-value 0.0475) 11 Figure 3 plots the evolution of aggregate rent dissipation in treatments LLLL, LLHH, and LHLH over the course of an experimental session. It reveals that the time-trend is remarkably similar across treatments, such that the relation between any one of the two heterogeneous treatments and the homogeneous benchmark does not change with experience of experimental subjects. Thus, subjects realize that their initial contest investments are too high, but even experience does not help to deliver the theoretical prediction that heterogeneity reduces (rather than increases) the aggregate rent-dissipation rate - subjects invest more in the heterogeneous treatments in all decision rounds.

Result 2 (Aggregate Effect of Heterogeneity). In contrast to the theoretical prediction, heterogeneity tends to increase rather than decrease the aggregate rent-dissipation rate in treatments LLHH and LHLH; the data allow us to reject Hypothesis 2.

Finally, Hypothesis 3 addresses the stage-specific effect of heterogeneity in treatments LLHH and LHLH. Broadly speaking, the hypothesis predicts that heterogeneity in a given stage should reduce rent dissipation in that stage. Thus, stage-1 rent dissipation is predicted to be higher in the treatment with homogeneous stage-1 interactions (LLHH), and stage-2 rent dissipation should be higher in LHLH where stage-2 interactions are often between contestants of the same type. The numbers in Table 2 display the opposite relations, however: $\mathbf{D R}_{1}$ is lower (and not higher) in LLHH than in LHLH (0.679 vs. 0.815 ), while $\mathbf{D R}_{2}$ is higher (and not lower) in LLHH than in LHLH (0.748 vs. 0.711). While the difference across treatments in stage 2 is modest and, according to panel (b) of Figure 4, not systematic across decision rounds, this is different in stage 1: According to panel (a) of Figure 4, the stage-1 rent-dissipation

\footnotetext{
${ }^{11}$ We use the random effect panel regression $\mathbf{D R}=\alpha+\beta *$ treat, where treat is a dummy for LLHH or LHLH, respectively. Standard errors are clustered on the session level. Since $H_{0}$ states that $\beta \leq 0$, we use a one-sided test on the estimated parameter $\beta$ for inference.
} 
Figure 3: DR in LLLL, LLHH and LHLH by Decision Round

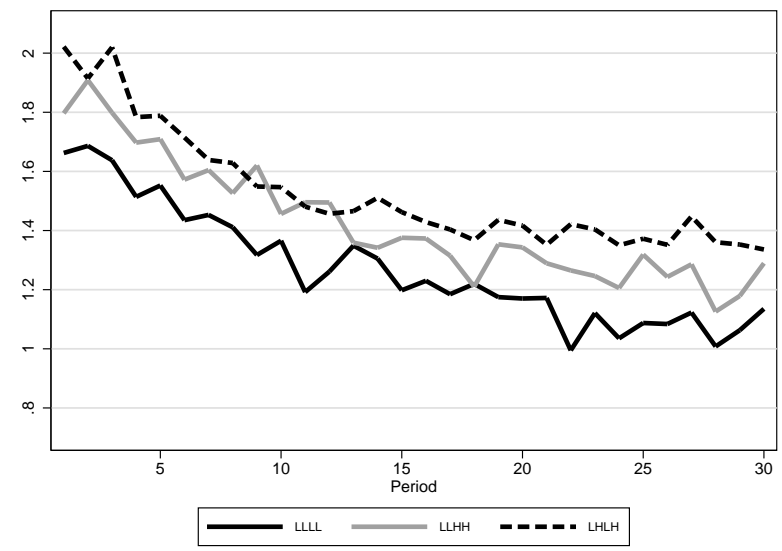

rate in LHLH is higher than in in LLHH in all decision rounds. Moreover, a statistical inference allows to reject Hypothesis $3(\mathrm{a})$ at the $10 \%$ level (p-value 0.095 ), while a p-value of 0.3285 does not allow us to reject Hypothesis $3(\mathrm{~b})$. We summarize these findings below:

Result 3 (Stage Effect of Heterogeneity). In contrast to the theoretical prediction, the stage-1 (stage-2) rent-dissipation rate is lower (slightly higher) in treatment LLHH than in LHLH; the data allow us to reject Hypothesis 3(a), while we cannot reject 3(b).

Overall, our results suggest that the behavior in our homogeneous treatments is qualitatively in line with theoretical predictions. In particular, the value of the cost parameter has no effect on contest investments by experimental subjects under homogeneity (Result 1). The effect of heterogeneity on rent-dissipation rates is not even qualitatively in line with equilibrium predictions, however, since cost-heterogeneity seems to have a positive rather than a negative impact on contest intensity: We find that the aggregate rent-dissipation rate is higher (and not lower) in both heterogeneous treatments (Result 2). Moreover, heterogeneity in stage 1 positively (and not negatively) affects the rent-dissipation rate in that stage, while heterogeneity in stage 2 has almost no effect on the rent-dissipation rate in that stage (Result 3).

\subsection{Disaggregating the Data by Cost-Type}

To shed some light on the question why the observed behavioral reaction to heterogeneity differs from the theoretical equilibrium predictions, we separately analyze the behavior of low- and high-cost subjects in each stage. In particular, we investigate how different types respond to heterogeneity in a particular stage of the contest.

Stage 2. The two-type setting allows for different interactions in stage 2: Either, the interaction is homogeneous and both subjects have high- or low investment costs (HH or LL), 
Figure 4: Rent-Dissipation in LLHH and LHLH by Stage and Decision Round

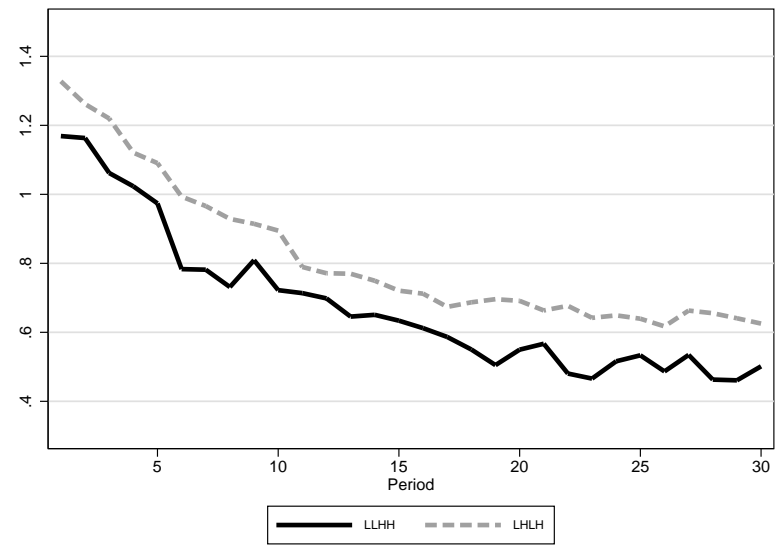

(a) Stage-1

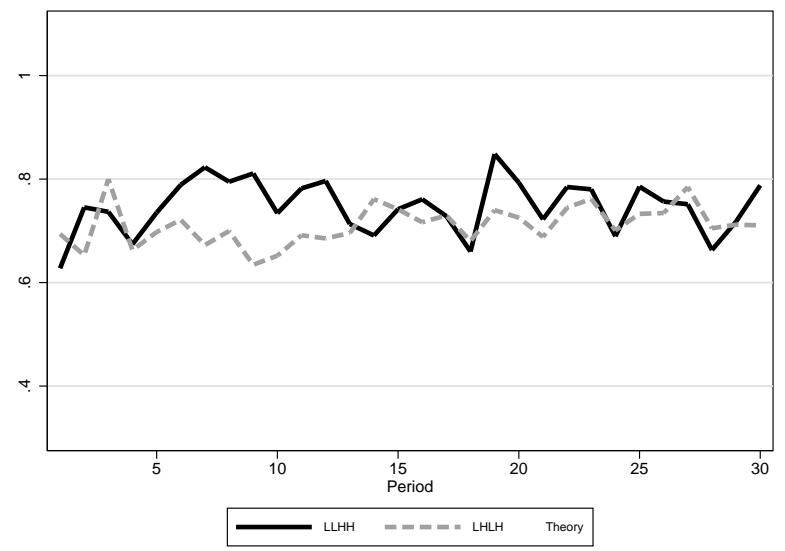

(b) Stage-2

respectively, or the interaction is heterogeneous and subjects with different types compete with each other ( $\mathrm{LH})$. To investigate how high-cost and low-cost subjects respond to heterogeneity in stage 2, we compare stage-2 expenditures of a particular type in homogeneous and heterogeneous interactions. The experimental design allows for two identification strategies: First, the fact that all potential stage-2 interactions may occur in treatment LHLH allows for a within-subject identification in a regression with fixed effects. Second, we can pool all stage-2 interactions of a certain type across treatments and then use a random effect regression for inference in a between-subject comparison.

Table 3 provides the observed means in stage-2 interactions LL, LH and HH for treatment LHLH as well as the averages for these interactions across all treatments. Consider first treatment LHLH. In line with the qualitative theoretical prediction, low-cost subjects expend significantly less in the heterogeneous interaction LH than in the homogeneous one (81.85 vs. 85.75, p-value 0.052) 12 Even though theory predicts an even more pronounced expenditure reduction for high-cost subjects, they expend slightly more in the heterogeneous interaction $\mathrm{LH}$ than in $\mathrm{HH}$ (83.63 vs. 83.03); the difference is insignificant, however (p-value 0.337). The observed pattern is similar if we consider the averages for homogeneous and heterogenous stage-2 interactions across all treatments ${ }^{13}$ Again, we find that low-cost subjects reduce their expenditures in response to heterogeneity ( 84.24 vs. 81.36 , p-value 0.007 ), while high-cost subjects tend to expend more in LH than in HH. The response to heterogeneity by high-cost subjects is more pronounced in the pooled data, however, and here the difference is statistically significant (p-value 0.050) ${ }^{14}$

\footnotetext{
${ }^{12}$ We use a fixed effect regression and cluster standard errors on the session level.

${ }^{13}$ Using a random effect panel regression with clustered standard errors, we cannot reject the null that the behavior in a particular stage-2 interaction (LL, LH, HH) is independent of the treatment. Details available from the authors upon request.

${ }^{14}$ Thus, we can reject the null that high-cost subjects expend the same amount or less in LH compared to
} 
Table 3: Stage-2 Expenditures by Cost-Type

\begin{tabular}{|c|c|c|c|c|c|c|}
\hline & \multicolumn{3}{|c|}{ only LHLH } & \multicolumn{3}{|c|}{ all treatments } \\
\hline & LL & LH & $\mathrm{HH}$ & LL & LH & $\mathrm{HH}$ \\
\hline L & $\begin{array}{c}85.78 \\
(60)\end{array}$ & $\begin{array}{c}81.85 \\
(58)\end{array}$ & - & $\begin{array}{c}\mathbf{8 4 . 2 4} \\
(60)\end{array}$ & $\begin{array}{c}\mathbf{8 1 . 3 6} \\
(58)\end{array}$ & - \\
\hline $\mathrm{H}$ & - & $\begin{array}{c}\mathbf{8 3 . 6 3} \\
(57)\end{array}$ & $\begin{array}{c}83.03 \\
(60)\end{array}$ & - & $\begin{array}{c}\mathbf{8 8 . 1 8} \\
(57)\end{array}$ & $\begin{array}{c}\mathbf{8 3 . 8 3} \\
(60)\end{array}$ \\
\hline
\end{tabular}

Taken together, we find that low-cost subjects respond to heterogeneity in stage 2 as theory predicts, while high-cost subjects do not - they tend to expend more and not less. The additional expenditures by high-cost subjects at least partly compensate for the expenditure reduction by low-cost subjects. This explains why heterogeneity has almost no effect on stage-2 expenditures, as established in Result 3 .

Stage 1. Table 4 provides the observed means in stage 1 by treatment and cost-type, as well as the theoretical predictions. Before we compare stage- 1 expenditures across treatments, note that the distinction between homogeneous and heterogeneous interactions is insufficient to analyze behavior in stage 1. As discussed in Section 2, the rent for which subjects compete in stage 1 is the right of a stage- 2 participation. This value depends on the expected stage- 2 opponent, however. In particular, everybody would rather compete with a high-cost than with a low-cost opponent in stage 2. Consequently, equilibrium expenditures by low-cost contestants are higher in stage 1 of treatment LLHH (where the investment costs of the stage-2 opponent are high) than in stage 1 of the homogeneous treatment LLLL (where the investment costs of the stage- 2 opponent are low), even though the stage- 1 interaction is homogeneous in both treatments. Similarly, equilibrium expenditures by high-cost contestants are lower in stage 1 of treatment LLHH (where the investment costs of the stage-2 opponent are low) than in stage 1 of the homogeneous treatment HHHH (where the investment costs of the stage2 opponent are high), even though the stage- 1 interaction is again homogeneous in both treatments. Thus, we can test whether subjects rationally react to different continuation values by comparing stage- 1 expenditures in the two homogeneous treatments with those in treatment LLHH. In addition, a comparison of stage- 1 expenditures in treatment LHLH (where stage-1 interactions are heterogeneous) with the homogeneous benchmarks LLLL and HHHH LL. 
Table 4: Stage-1 Expenditures by Cost-Type

\begin{tabular}{ccccc}
\hline \hline & LLLL & LLHH & LHLH & HHHH \\
\hline L & $\mathbf{3 4 . 3 3}$ & $\mathbf{4 6 . 1 0}$ & $\mathbf{4 7 . 6 6}$ & - \\
& $(15)$ & $(22)$ & $(14)$ & \\
$\mathrm{H}$ & - & $\mathbf{3 5 . 3 9}$ & $\mathbf{5 0 . 1 6}$ & $\mathbf{3 2 . 7 9}$ \\
& & $(9)$ & $(9)$ & $(15)$ \\
\hline \hline
\end{tabular}

Bold numbers denote rent-dissipation rate averages over all rounds of experimental sessions. Theoretical benchmarks are provided in parentheses below the respective measure.

allows us to test how subjects respond to heterogeneity in stage 1.

Consider the continuation-value effect first. In line with the qualitative theoretical prediction, low-cost subjects significantly increase their expenditures in response to the higher stage-1 continuation value in treatment LLHH (p-value 0.000) ${ }^{15}$ According to Table 4 , stage-1 expenditures amount to 34.33 units in LLLL, compared to 46.10 units in LLHH. Panel (a) of Figure 5 plots stage-1 expenditures for low-cost subjects over all rounds of the experiment and shows that this relation holds in all rounds of an experimental session. The reaction of high-cost subjects to the changing continuation value is not in line with theoretical predictions, however. High-cost subjects slightly increase (rather than decrease) stage-1 expenditures from 32.79 in treatment HHHH to 35.39 in LLHH, even though their continuation value is lower in LLHH. Note, however, that this behavioral change is statistically insignificant (pvalue 0.861 ). Moreover, panel (b) of Figure 5, which plots stage-1 expenditures for high-cost subjects over all rounds of the experiment, shows that the relation reflected in averages does only hold in the first part of an experimental session, while we observe that stage-1 expenditures by high-cost subjects are lower in later decision rounds. This suggests that subjects need some experience to realize that their stage- 1 continuation value is comparably low in treatment LLHH.

Next, consider the effect of heterogeneity in the current interaction. The theoretical model predicts that both low-cost and high-cost contestants expend less in the heterogeneous stage1 interaction of treatment LHLH than in the homogeneous stage- 1 interactions of treatments LLLL and HHHH, respectively. Moreover, the effect is predicted to be more pronounced for contestants with high investment costs. Result 3 suggests that we observe the opposite in the experiments, however. A disaggregate analysis of stage-1 behavior reveals that both types expend more in case of heterogeneity: Low-cost subjects increase expenditures from

\footnotetext{
${ }^{15}$ We use a random effect panel regression, as described in Footnote 11 , for inference.
} 
Figure 5: Stage-1 Expenditures by Cost-Type and Decision Round

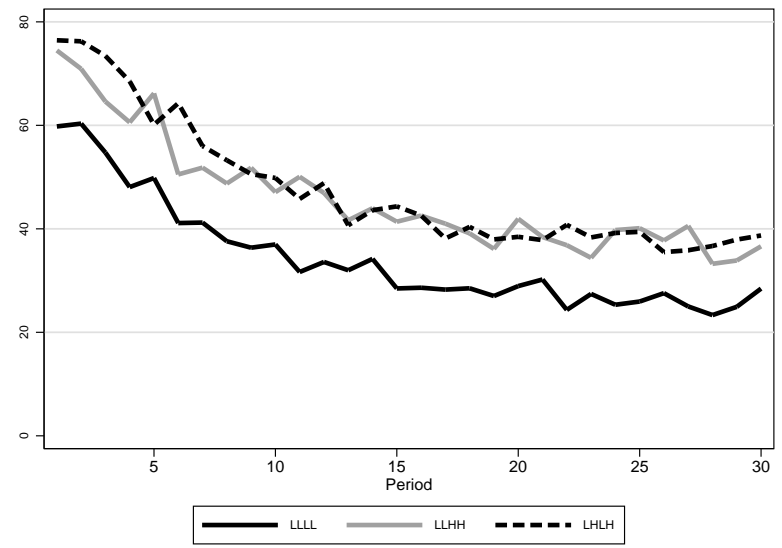

(a) Low-cost (L)

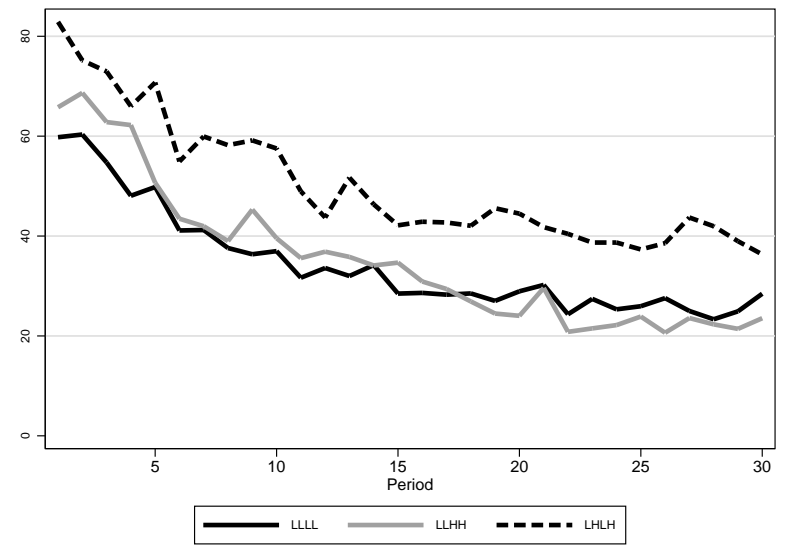

(b) High-cost (H)

34.33 to 47.66 units, and high-cost subjects expend 50.16 units in stage 1 of treatment LHLH, compared to only 32.79 units in HHHH. Those numbers already indicate that we can reject the null that low-cost and high-cost subjects (weakly) reduce expenditures ${ }^{16}$ Interestingly, the pattern we observe in session means does not change with experience: Figure 5 plots stage-1 expenditures over all rounds of the experiment in the three treatments and shows that stage-1 expenditures by both low-cost and high-cost subjects are strictly higher in the heterogeneous interactions of treatment LHLH than in the homogeneous treatment LLLL.

\subsection{Discussion of Results and Potential Explanations}

The experimental data for the two homogeneous treatments is qualitatively in line with both the existing experimental evidence and the theoretical prediction. However, in stark contrast to the theoretical benchmark the experimental results indicate that the overall effect of heterogeneity on dissipation rates in a multi-stage contest is positive rather than negative. This already manifests itself in treatment LLHH where theory predicts that dissipation rates are (slightly) lower than in the homogeneous benchmark due to heterogeneity in stage 2, while we can reject a negative effect at the 10\%-level in the experimental data. The positive effect of heterogeneity is more pronounced in treatment LHLH were theory again predicts that heterogeneity reduces the aggregate rent-dissipation rate, while we observe a strong increase and can reject a negative aggregate effect at the 5\%-level. The separate analysis by stage and cost-type revealed that the deviation from the theoretical benchmark is particularly pronounced in stage 1 of LHLH: While both types should expend less in stage- 1 of treatment LHLH than in a homogeneous benchmark, they expend significantly more. Subsequently, we will discuss potential explanations for this behavior.

\footnotetext{
${ }^{16}$ The respective p-values are 0.025 for type $\mathrm{L}$, and 0.011 for type $\mathrm{H}$ subjects.
} 
Budget Constraints. Even though the budget is not binding in any stage in the theoretical benchmark, the high degree of over-dissipation in all treatments and stages could change that in principle. Harbaugh and Klumpp (2005) theoretically analyze behavior in a two-stage contest that is similar to our setting LHLH. Under the assumption that the budget has no intrinsic value, they show that 'underdogs' are more likely to win against 'favourites' in stage 1 than in stage 2 , since the former expend relatively more of their endowment in stage 1 . In line with this prediction, we observe that stage-1 expenditures by high-cost subjects exceed the theoretical benchmark by the factor 5, while low-cost subjects spend only three times as much as the model without budget constraints would predict. While this observation is broadly consistent with a binding budget constraint, several details in the experimental data undermine the plausibility of this explanation: First, the whole endowment is expended in less than $8 \%$ of all interactions in LHLH, and the pattern we observe does not change if these observations are excluded. Second, stage-2 expenditures in a particular interaction do not differ across treatments, even though stage-1 expenditures do. Stage-2 expenditures should differ across treatments, however, if the endowment were binding in LHLH, but not in homogeneous treatments, where the whole endowment is dissipated in less than $4 \%$ of all cases. Finally, the endowment has an intrinsic value in our experimental treatments and control questions indicate that subjects realize that whatever remains of the endowment is paid out in cash. Thus, the results of Harbaugh and Klumpp (2005) from a model with a budget without intrinsic value are unlikely to be relevant for our framework, even if the endowment were binding.

High Strategic Complexity and Mistakes. We are not the first who find that the deviation from the benchmark is particularly pronounced in stage 1 of a two-stage pairwise elimination contest - Sheremeta (2010b) and Altmann, Falk, and Wibral (2012), for example, report that over-dissipation is much higher in stage 1 than in stage 2 of a two-stage contest with homogeneous contestants. A prominent explanation for this observation relies on the idea that it is cognitively more demanding to determine optimal behavior in stage 1 than in stage 2 , since contestants need to form expectations about their potential opponents' stage2 behavior to determine the value of winning the stage- 1 interaction. Thus, the strategic complexity in stage 1 of a multi-stage contest is high, which may cause excess expenditures. Both aforementioned studies find evidence in support of this story: Sheremeta (2010b) reports that the degree of stage-1 over-dissipation decreases in a homogeneous two-stage elimination contest as subjects become more experienced, while stage-2 over-dissipation remains constant - this suggests that subjects need experience to correctly understand the complex strategic decision they face in stage 1, while this problem is less pronounced in stage 2. Altmann, Falk, 
Table 5: Main Results (decision rounds 21-30)

\begin{tabular}{lcccccc}
\hline \hline & \multicolumn{2}{c}{ Homogeneity } & & \multicolumn{2}{c}{ Heterogeneity } \\
\cline { 2 - 3 } \cline { 6 - 6 } & LLLL & HHHH & & LLHH & LHLH \\
\hline \multirow{2}{*}{$\mathbf{D R}$} & $\mathbf{1 . 0 8 2}$ & $\mathbf{1 . 1 6 7}$ & & $\mathbf{1 . 2 4 5}$ & $\mathbf{1 . 3 7 5}$ \\
& $(0.750)$ & $(0.750)$ & & $(0.738)$ & $(0.683)$ \\
$\mathbf{D R}_{1}$ & $\mathbf{0 . 4 3 8}$ & $\mathbf{0 . 4 4 0}$ & & $\mathbf{0 . 5 0 1}$ & $\mathbf{0 . 6 4 7}$ \\
& $(0.250)$ & $(0.250)$ & & $(0.258)$ & $(0.192)$ \\
$\mathbf{D R}_{2}$ & $\mathbf{0 . 6 4 5}$ & $\mathbf{0 . 7 2 7}$ & & $\mathbf{0 . 7 4 4}$ & $\mathbf{0 . 7 2 7}$ \\
& $(0.500)$ & $(0.500)$ & & $(0.479)$ & $(0.491)$ \\
& & & & \\
\hline
\end{tabular}

Note: Bold numbers denote rent-dissipation rate averages over rounds 21-30 of the experimental sessions and are defined as in Table 2

and Wibral (2012) test the complexity hypothesis with a different experimental design, since subjects in their treatments participate in only one two-stage contest without repetition, which does not allow for learning due to experience. They use a control treatment where the stage- 2 winner is determined by a coin toss rather than by stage- 2 investment choices which arguably reduces the strategic complexity in stage 1. Consistent with the hypothesis that strategic complexity is in part responsible for over-dissipation in stage 1, they find that stage-1 over-dissipation is lower in the control than in the main treatment.

If strategic complexity is a main driver for behavior in stage 1 of our two-stage contest, then it arguably should be particularly relevant in stage- 1 of treatment LHLH, since heterogeneity in both stage-1 interactions introduces uncertainty about the configuration of types in stage 2 in this treatment. In line with this argument, Table 2 reveals that over-dissipation is not only higher in stage 1 than in stage 2 in all treatments, but also most pronounced in treatment LHLH. In particular, average stage-1 rent-dissipation rates are between two-times (in LLLL) and four-times (in LHLH) as high as the respective benchmark, while stage-2 averages exceed their equilibrium predictions by only about $40 \%$ in the homogeneous treatments LLLL and HHHH, and by only approximately $55 \%$ in the heterogeneous treatment LLHH. In line with the evidence reported by Sheremeta (2010b) figures 2 and 4 reveal that stage-1 expenditures decrease as subjects become more experienced, while the dissipation rate in stage 2 remains rather constant. This pattern is also confirmed in a regression analysis which uses period dummies for all but the last decision round to explain stage- 1 and stage- 2 rentdissipation rates ${ }^{17}$ In addition, the regressions reveal that the effect of experience on stage-1

\footnotetext{
${ }^{17}$ We use separate random effect regression for each treatment and cluster standard errors on the session level. Period dummies exhibit a clear downward trend in stage 1, but are insignificant in stage 2 .
} 
expenditures disappears over the course of an experimental session. Interestingly, however, the regressions also provide support for the argument that the strategic complexity is particularly high in stage 1 of treatment LHLH. In particular, the estimations suggest that the effect of experience on stage-1 expenditures lasts longer in treatment LHLH than in the homogeneous treatments - while only the first ten period dummies are significantly different from zero in LLLL and HHHH, this holds for the first seventeen periods in LHLH. While all this evidence is in line with the hypothesis that complexity is an important driver for behavior, other evidence suggests that it is unlikely to be the main explanation for our finding that heterogeneity increases rather than decreases rent dissipation: Table 5 provides average rent-dissipation rates by treatment and stage for the last ten decision rounds where we find no experience effect in any treatment. The numbers suggests that all previously established relations across treatments do still hold, and formal tests confirm this conjecture ${ }^{18}$ Thus, it is unlikely that mistakes due to the high degree of strategic complexity are responsible for the positive effect of heterogeneity on stage-1 expenditures by high- and low-cost contestants that we observe.

Joy of Winning or Competing. As discussed above, previous studies found evidence that the high strategic complexity is at least partly responsible for the finding that over-dissipation relative to theoretical predictions is much higher in stage 1 than in stage 2 . The same studies also report, however, that this pattern prevails even when accounting for experience or when the strategic complexity is directly reduced in a control treatment. To account for this remaining relative over-dissipation in stage 1, Parco et al. (2005) and Sheremeta (2010b) consider a behavioral model where winning has a value per se. Since the continuation value in stage 1 is much lower than the prize awarded in stage 2 in a 'winner-takes-all' contest, the relative effect of this value of winning on expenditures should be more pronounced in stage 1, which is in line with observed behavior by experimental subjects. A related hypothesis by Altmann, Falk, and Wibral (2012) is that contestants may not only derive extra utility from winning a competition, but from competing per se. In that case, subjects who enjoy future competition should again invest relatively more in stage 1 than in stage 2 , since stage- 1 losers are eliminated from the contest and thus excluded from future competition, while the contest ends for everybody after stage 2 .

As the aforementioned studies, we observe that stage-1 over-dissipation is still higher than stage-2 over-dissipation in all treatments even after accounting for experience. Thus, the 'joy of winning' or 'joy of competing' argument might also be relevant in our treatments.

\footnotetext{
${ }^{18}$ The p-values are very similar: For Hypothesis 1 we obtain 0.613 for (a), 0.978 for (b), and 0.111 for (c); for Hypothesis 2 we get 0.055 for (a) and 0.027 for (b); for Hypothesis 3 , the respective p-values are 0.048 for (a) and 0.980 for (b). The only thing that changes in later decision rounds is that high-cost subjects expend less in stage 1 of treatment LLHH than in HHHH, as already discussed in subsection 4.2 above.
} 
While any one of these two arguments can explain the qualitative pattern we observe across stages in our treatments, the arguments must be combined with an approach put forth by Chen, Ham, and Lim (2011) to explain why heterogeneity increases rather than decreases rent dissipation. Chen et al. (2011) develop a behavioral model of a contest with asymmetric contestants and suggest that the 'joy of winning' depends on the type of the opponent. In particular, they assume that underdogs derive additional utility from beating a favourite, while losing against an underdog is particularly unattractive for a favourite. In the context of our multi-stage model, this assumption would imply that the 'joy of competing' argument is particularly important for heterogeneous interactions in stage 1. Intuitively, failing to make it to the next stage is less of an issue for a low-cost agent when the opponent is equally talented, but extremely unattractive when competing against an opponent with worse odds. Thus, low-cost subjects react to stage- 1 heterogeneity by expending much more, while they expend less in heterogeneous stage-2 interactions where the 'joy of competing' argument is irrelevant. Similarly, if winning against an advantaged opponent delivers an additional 'joy of winning' for a high-cost contestants, this would imply that she bids more as an underdog than when facing an equally strong opponent. Thus, this story would be in line with what we observe in both stages.

\section{Concluding Remarks}

This paper has analyzed how heterogeneity in contestants' investment cost parameters affects the competition intensity in a dynamic elimination contest. While the theoretical model suggest that the level of investment costs has no effect on the rent-dissipation rate in a two-stage pairwise elimination contest with homogeneous participants, it predicts that cost heterogeneity between competing contestants matters. In particular, heterogeneity is predicted to reduce the rent-dissipation rate, no matter whether stage- 1 or stage- 2 interactions are between heterogenous contestants. The experimental data for the homogeneous treatments is qualitatively well in line with theoretical predictions. This is not the case for heterogeneous settings, however. In contrast to the theoretical prediction, we observe a pronounced positive effect of stage-1 heterogeneity on competition intensity in that stage, while the effect of stage-2 heterogeneity is close to zero. A more thorough analysis of the experimental data suggests that confusion is not a plausible explanation for our findings. Instead, it seem that behavioral factors such as type specific 'joy of winning' or 'joy of competing' is responsible for the patterns we observe.

While our results show that the effect of heterogeneity on competition intensity can be positive in multi-stage contests, the exact circumstances under which this positive effect arises 
are not yet clear. It is an open question whether our findings carry over to multi-stage pyramid contests that pool participants in each stage. It seems reasonable that underdogs slack off if they compete against several rather than just one strong opponent at the same time, for example. Moreover, the relation between competition intensity and stage-1 heterogeneity might be U-shaped rather than monotonic. Then, it could well be that the effect of increasing heterogeneity becomes negative for high levels of heterogeneity. While investigating the effect of increasing the degree of heterogeneity seems an interesting avenue for future research, it should be mentioned that the degree of heterogeneity implemented in our experiments is already relatively high - with our parametrization underdogs are $50 \%$ less productive than favourites which seems quite a lot for a real world competition. 


\section{References}

Altmann, S., A. Falk, and M. Wibral (2012): "Promotions and Incentives: The Case of Multi-Stage Elimination Tournaments," Journal of Labor Economics, 30(1), 149-174.

Amegashie, J., C. B. Cadsby, and Y. Song (2007): "Competitive Burnout: Theory and Experimental Evidence," Games and Economic Behavior, 59, 213-239.

Anderson, L. R., And S. L. Stafford (2003): "An Experimental Analysis of Rent Seeking under Varying Competitive Conditions," Public Choice, 115, 199-216.

Bull, C., A. Schotter, and K. Weigelt (1987): "Tournaments and Piece Rates: An Experimental Study," Journal of Political Economy, 95(1), 1-33.

Chen, H., S. H. Ham, and N. Lim (2011): "Designing Multiperson Tournaments with Asymmetric Contestants: An Experimental Study," Management Science, 57(5), 864-883.

Cornes, R., and R. Hartley (2005): "Asymmetric Contests with General Technologies," Economic Theory, 26, 923-946.

Dechenaux, E., D. Kovenock, and R. M. Sheremeta (2012): "A Survey of Experimental Research on Contests, All-Pay Auctions and Tournaments," Working Paper.

Fischbacher, U. (2007): "Z-Tree, Zurich Toolbox for Readymade Economic Experiments," Experimental Economics, 10, 171-178.

Fu, Q., And J. Lu (2013): "The Optimal Multi-Stage Contest," Economic Theory, forthcoming.

Gradstein, M., And K. A. Konrad (1999): "Orchestrating Rent Seeking Contests," Economic Journal, 109(458), 536-545.

Greiner, B. (2004): "An Online Recruitment Sysmte for Economic Experiments," in Forschung und wissenschaftliches Rechnen 2003, pp. 79-93. GWDDG Bericht der 63. Gesellschaft für Wissenschaftliche Datenverarbeitung, Göttingen, K. Kremer and V. Macho (eds.).

Groh, C., B. Moldovanu, A. Sela, and U. Sunde (2012): "Optimal Seedings in Elimination Tournaments," Economic Theory, 49(1), 59-80.

Harbaugh, R., and T. Klumpp (2005): "Early Round Upsets and Championship Blowouts," Economic Inquiry, 43(2), 316-329.

Höchtl, W., R. Kerschbamer, R. Stracke, and U. Sunde (2011): "Incentives vs. Selection in Promotion Tournaments: Can a Designer Kill Two Birds with One Stone?," IZA Discussion paper.

Kimbrough, E. O., R. M. Sheremeta, and T. Shields (2011): "Resolving Conflicts by a Random Device," Working Paper.

KRÄKEL, M. (2013): "Optimal Seedings in Elimination Tournaments Revisited," SAET Bulletin (forthcoming).

Nti, K. O. (1999): "Rent-Seeking with Asymmetric Valuations," Public Choice, 98, 415430. 
Parco, J. E., A. Rapoport, and W. Amaldoss (2005): "Two-Stage Contests with Budget Constraints: An Experimental Study," Journal of Mathematical Psychology, 49, 320-338.

Rosen, S. (1986): "Prizes and Incentives in Elimination Tournaments," American Economic Review, 76(4), 701-715.

Schotter, A., and K. Weigelt (1992): "Asymmetric Tournaments, Equal Opportunity Laws, and Affirmative Action: Some Experimental Results," Quarterly Journal of Economics, 107(2), 511-539.

Sheremeta, R. M. (2010a): "Expenditures and Information Disclosure in Two-Stage Political Contests," Journal of Conflict Resolution, 54, 771-798.

- (2010b): "Experimental Comparison of Multi-Stage and One-Stage Contests," Games and Economic Behavior, 68, 731-747.

(2013): "Overbidding and Heterogeneous Behavior in Contest Experiments," Journal of Economic Surveys, 27, 491-514.

Stein, W. E., and A. Rapoport (2004): "Asymmetric Two-Stage Group Rent-Seeking: Comparison of Two Contest Structures," Public Choice, 124, 309-328.

(2005): "Symmetric Two-Stage Contests with Budget Contraints," Public Choice, $124,309-328$.

Stracke, R. (2013): "Contest Design and Heterogeneity," Economics Letters, 121, 4-7.

Stracke, R., W. Höchtl, R. Kerschbamer, and U. Sunde (2012): "Optimal Prizes in Dynamic Elimination Contests: Theory and Experimental Evidence," Working Paper, University of St. Gallen.

Tullock, G. (1980): "Efficient Rent-Seeking," in Toward a Theory of the Rent-Seeking Society. J.M. Buchanan and R.D. Tollison and G. Tullock (Eds.). Texas A\&M Press, College Station, p. 97-112. 


\section{Appendix}

\section{A Derivation of Equilibrium Efforts}

\section{A.1 Solution for Stage 2}

Assume that two contestants $i$ and $j$ with cost parameters $c_{i}$ and $c_{j}$, respectively, compete against each other in stage 2 . The optimization problems of these two workers, who maximizes their stage-2 payoff $\Pi_{2 i}$ and $\Pi_{2 j}$, respectively, by choosing an optimal level of investment $x_{2 i}$ $\left(x_{2 j}\right)$, read as follows: 19

$$
\begin{aligned}
& \max _{x_{2 i} \geq 0} \Pi_{2 i}=\frac{x_{2 i}}{x_{2 i}+x_{2 j}} R-c_{i} x_{2 i}, \\
& \max _{x_{2 j} \geq 0} \Pi_{2 j}=\frac{x_{2 j}}{x_{2 i}+x_{2 j}} R-c_{j} x_{2 j} .
\end{aligned}
$$

First order conditions are necessary as well as sufficient in any pair-wise interaction for the lottery CSF (see Nti, 1999, or Cornes and Hartley, 2005). The combination of first-order conditions implies equilibrium efforts

$$
x_{2 i}^{*}=\frac{c_{j}}{\left(c_{i}+c_{j}\right)^{2}} R \quad \text { and } \quad x_{2 j}^{*}=\frac{c_{i}}{\left(c_{i}+c_{j}\right)^{2}} R
$$

respectively. Inserting optimal actions in the two objective functions gives the expected equilibrium payoffs

$$
\Pi_{2 i}^{*}=\frac{c_{j}^{2}}{\left(c_{i}+c_{j}\right)^{2}} R \quad \text { and } \quad \Pi_{2 j}^{*}=\frac{c_{i}^{2}}{\left(c_{i}+c_{j}\right)^{2}} R
$$

Equations (4) and (5) characterize equilibrium investments and payoffs, respectively, for any possible combination of types, i.e., for LL, LH, and HH. In the main text of this paper, the particular tournament environment considered (that is, LL, LH, HH, LLHH, LHLH, LLLL or HHHH) is in parentheses - as in $x_{2 i}(\mathrm{LL})$ or $\Pi_{2 i}(\mathrm{LL})$, for example - or is omitted when there is no risk of confusion.

\section{A.2 Solution for Stage 1}

In stage 1 contestants compete in two pairwise interactions against each other. Suppose contestant $i$ competes with $j$ and contestant $k$ with $l$. We consider the optimization problems of $i$ and $j$ with

$$
\begin{aligned}
& \max _{x_{1 i} \geq 0} \Pi_{1 i}\left(x_{1 i}, x_{1 j}\right)=\frac{x_{1 i}}{x_{1 i}+x_{1 j}} C V_{i}-c_{i} x_{1 i} \\
& \max _{x_{1 j} \geq 0} \Pi_{1 j}\left(x_{1 i}, x_{1 j}\right)=\frac{x_{1 j}}{x_{1 i}+x_{1 j}} C V_{j}-c_{j} x_{1 j}
\end{aligned}
$$

The optimization problems for contestant $k$ and $l$ can be formulated accordingly and are omitted here. For given continuation values the first order conditions are

$$
x_{1 j} \cdot C V_{i}-c_{i}\left(x_{1 i}+x_{1 j}\right)^{2}=0 \quad \text { and } \quad x_{1 i} \cdot C V_{j}-c_{j}\left(x_{1 i}+x_{1 j}\right)^{2}=0 .
$$

\footnotetext{
${ }^{19}$ Throughout the paper the first subscript of the variables $\Pi$ and $x$ indicates the stage, while the second subscript indicates the player.
} 
Combining the first order conditions of contestants $i$ and $j$ equilibrium investments in stage 1 are

$$
x_{1 i}^{*}=\frac{c_{j} C V_{i} C V_{j}}{\left(c_{i} C V_{j}+c_{j} C V_{i}\right)^{2}} C V_{i} \quad \text { and } \quad x_{1 j}^{*}=\frac{c_{i} C V_{j} C V_{i}}{\left(c_{i} C V_{j}+c_{j} C V_{i}\right)^{2}} C V_{j}
$$

The continuation values are affected by the seeding of types in stage 1 . Thus, we derive the explicit expressions for equilibrium investments separately for the homogenous settings and the heterogenous setting LLHH and LHLH.

Homogenous Settings LLLL and HHHH. In the case where all contestants have same costs of investment $c_{i}=c_{j}=c_{k}=c_{l}>0$ each contestant competes against an agent of the same type in stage-2. Since contestants are symmetric and continuation values are the same for each contestant consider without loss of generality the continuation value of agent $i$ which is determined by the respective stage- 2 equilibrium payoff

$$
C V_{i}=\frac{R}{4}
$$

Inserting this expression in (7) gives following equilibrium effort level

$$
x_{1 i}^{*}=\frac{R}{16 c_{i}},
$$

where investment costs of all contestants could be either high or low $\left(c_{\mathrm{H}}>c_{\mathrm{L}}\right)$.

Heterogeneous Setting LLHH. In setting LLHH each contestant knows the type of the opponent in stage 2 for sure. Thus, an agent with low costs $c_{L}$ (high $\operatorname{costs} c_{H}$ ) knows that he will face an agent with high $\operatorname{costs} c_{H}$ (low $\left.\operatorname{costs} c_{L}\right)$. Therefore the continuation value of an agent $i$ is determined by the respective stage- 2 equilibrium profit $\Pi_{2 i}(\mathrm{LH})$ derived in (5) for a mixed interaction between a low cost and a high cost contestant. Continuation values for a low cost agent $\left(C V_{L}\right)$ and a high cost agent $\left(C V_{H}\right)$ read as follows

$$
C V_{L}=\Pi_{2 \mathrm{~L}}^{*}(\mathrm{LH})=\frac{c_{\mathrm{H}}^{2}}{\left(c_{\mathrm{L}}+c_{\mathrm{H}}\right)^{2}} R \quad \text { and } \quad C V_{H}=\Pi_{2 \mathrm{H}}^{*}(\mathrm{LH})=\frac{c_{\mathrm{L}}^{2}}{\left(c_{\mathrm{L}}+c_{\mathrm{H}}\right)^{2}} R
$$

Inserting continuation values in (7) delivers stage-1 equilibrium investments

$$
x_{1 \mathrm{~L}}^{*}(\mathrm{LLHH})=\frac{c_{\mathrm{H}}^{2}}{4 c_{\mathrm{L}}\left(c_{\mathrm{L}}+c_{\mathrm{H}}\right)^{2}} R \quad \text { and } \quad x_{1 \mathrm{H}}^{*}(\mathrm{LLHH})=\frac{c_{\mathrm{L}}^{2}}{4 c_{\mathrm{H}}\left(c_{\mathrm{L}}+c_{\mathrm{H}}\right)^{2}} R .
$$

Heterogeneous Setting LHLH. Whereas the derivation of equilibrium effort levels in setting LLHH is straightforward, it needs more attention in setting LHLH because continuation values are determined endogenously ${ }^{20}$.

We assume (without loss of generality) that contestants $i$ and $k$ have low costs, whereas contestants $j$ and $l$ have high costs, and that the two pairwise stage- 1 interactions are between

\footnotetext{
${ }^{20}$ Whereas continuation values in setting LLHH are solely determined by the payoff of interaction LH in stage 2 there are 3 different possible interactions in stage- 2 of setting LHLH, namely LH, LL or HH. Thus continuation values are expected values now.
} 
contestants $i$ and $j$, and between contestants $k$ and $l$, respectively. In each interaction both contestants choose their optimal stage-1 effort, given equilibrium behavior in any potential stage-2 interaction. Combining the first order conditions derived in (6) we obtain two expressions that define a relation between equilibrium effort choices of contestants within each interaction, namely

$$
\frac{x_{1 i}}{x_{1 j}}=\frac{c_{\mathrm{H}}}{c_{\mathrm{L}}} \frac{C V_{i}}{C V_{j}} \quad \text { and } \quad \frac{x_{1 k}}{x_{1 l}}=\frac{c_{\mathrm{H}}}{c_{\mathrm{L}}} \frac{C V_{k}}{C V_{l}},
$$

respectively. These expressions show that each stage- 1 interaction is a tournament between agents with different costs and endogenously different valuations of winning. While the costs of investment differ by construction, the difference of the value for winning is a result of the tournament structure: Reaching stage 2 is more valuable for low cost than for high cost contestants.

The continuation values are endogenously determined by the probabilities of entering the different actions in stage 2 (which are determined by the investments in the other pairwise stage-1 interaction) and the respective equilibrium payoffs. They read as follows:

$$
\begin{gathered}
C V_{i}=\frac{x_{1 \mathrm{k}}}{x_{1 \mathrm{k}}+x_{11}} \cdot \Pi_{2 \mathrm{~L}}^{*}(\mathrm{LL})+\left(1-\frac{x_{1 \mathrm{k}}}{x_{1 \mathrm{k}}+x_{11 \mathrm{k}}}\right) \cdot \Pi_{2 \mathrm{~L}}^{*}(\mathrm{LH}) ; \\
C V_{j}=\frac{x_{1 \mathrm{k}}}{x_{1 \mathrm{k}}+x_{11}} \cdot \Pi_{2 \mathrm{H}}^{*}(\mathrm{LH})+\left(1-\frac{x_{1 \mathrm{k}}}{x_{1 \mathrm{k}}+x_{11}}\right) \cdot \Pi_{2 \mathrm{H}}^{*}(\mathrm{HH}) .
\end{gathered}
$$

Similarly, the continuation values in the other stage-2 interaction between contestant $k$ and $l$ depend on the behavior of agents $i$ and $j$.

We proceed now to the solution of the problem, which comprises two participants which differ in their investment costs and their valuation. As mentioned previously, any tournament with two heterogenous participants has a unique, interior equilibrium for the chosen contest success function (Cornes and Hartley 2005, Nti 1999). Consequently, each of the two pairwise stage-1 interactions has a unique equilibrium for each pair of continuation values. What remains to be shown is that the two expressions in (11) can be satisfied jointly. Inserting the continuation values in (11) and simplifying gives

$$
\frac{x_{1 i}}{x_{1 j}}=\frac{c_{\mathrm{H}}}{c_{\mathrm{L}}} \frac{\left(c_{\mathrm{L}}+c_{\mathrm{H}}\right)^{2} \frac{x_{k 1}}{x_{l 1}}+4 c_{\mathrm{H}}^{2}}{4 c_{\mathrm{L}}^{2} \frac{x_{k 1}}{x_{l 1}}+\left(c_{\mathrm{L}}+c_{\mathrm{H}}\right)^{2}} \quad \text { and } \quad \frac{x_{k 1}}{x_{l 1}}=\frac{c_{\mathrm{H}}}{c_{\mathrm{L}}} \frac{\left(c_{\mathrm{L}}+c_{\mathrm{H}}\right)^{2} \frac{x_{i 1}}{x_{j 1}}+4 c_{\mathrm{H}}^{2}}{4 c_{\mathrm{L}}^{2} \frac{x_{i 1}}{x_{j 1}}+\left(c_{\mathrm{L}}+c_{\mathrm{H}}\right)^{2}} \text {. }
$$

System (12) consists of two equations in the two unknowns $\frac{x_{1 i}^{*}}{x_{1 j}^{*}}$ and $\frac{x_{1 k}^{*}}{x_{1 l}^{*}}$, respectively. Note that the two equations are symmetric, since the two contestants in each of the two stage-1 interactions face identical optimization problems. This implies that $x_{1 \mathrm{~L}}^{*} \equiv x_{1 i}^{*}=x_{1 k}^{*}$ and $x_{1 \mathrm{H}}^{*} \equiv x_{1 j}^{*}=x_{1 l}^{*}$ do hold in the symmetric equilibrium ${ }^{21}$ Combining these conditions with (12) gives:

$$
\frac{x_{1 \mathrm{~L}}^{*}}{x_{1 \mathrm{H}}^{*}}=\frac{c_{\mathrm{H}}}{c_{\mathrm{L}}} \frac{\left(c_{\mathrm{L}}+c_{\mathrm{H}}\right)^{2} \frac{x_{1 \mathrm{~L}}^{*}}{x_{1 \mathrm{H}}^{*}}+4 c_{\mathrm{H}}^{2}}{4 c_{\mathrm{L}}^{2} \frac{x_{1 \mathrm{~L}}^{*}}{x_{1 \mathrm{H}}^{*}}+\left(c_{\mathrm{L}}+c_{\mathrm{H}}\right)^{2}}
$$

\footnotetext{
${ }^{21}$ The symmetric equilibrium exists for any degree of heterogeneity and is unique. Intuitively, one must show that the graphs of the two relations in 12 have a unique intersection in the domain defined by $\frac{x_{1 j}^{*}}{x_{1 i}^{*}} \in[0,1]$ and $\frac{x_{11}^{*}}{x_{1 k}^{*}} \in[0,1]$. It suffices to consider this domain, since the assumption of lower investment costs and the resulting higher value of winning of contestants with low costs imply $x_{1 i}^{*} \geq x_{1 j}^{*}$ and $x_{1 k}^{*} \geq x_{1 l}^{*}$, respectively. This follows from (11). Details available upon request from the corresponding author.
} 


$$
\begin{aligned}
& \Leftrightarrow 0=4 c_{\mathrm{L}}^{2}\left[\frac{x_{1 \mathrm{~L}}^{*}}{x_{1 \mathrm{H}}^{*}}\right]^{2}+\left(1-\frac{c_{\mathrm{H}}}{c_{\mathrm{L}}}\right)\left(c_{\mathrm{L}}+c_{\mathrm{H}}\right)^{2}\left[\frac{x_{1 \mathrm{~L}}^{*}}{x_{1 \mathrm{H}}^{*}}\right]-4 \frac{c_{\mathrm{H}}^{3}}{c_{\mathrm{L}}} \\
& \Leftrightarrow \frac{x_{1 \mathrm{~L}}^{*}}{x_{1 \mathrm{H}}^{*}}=F^{*}\left(c_{\mathrm{L}}, c_{\mathrm{H}}\right),
\end{aligned}
$$

where

$$
F^{*}\left(c_{\mathrm{L}}, c_{\mathrm{H}}\right)=\frac{\left(c_{\mathrm{H}}-c_{\mathrm{L}}\right)\left(c_{\mathrm{L}}+c_{\mathrm{H}}\right)^{2}+\sqrt{64 c_{\mathrm{H}}^{3} c_{\mathrm{L}}^{3}+\left(c_{\mathrm{L}}-c_{\mathrm{H}}\right)^{2}\left(c_{\mathrm{L}}+c_{\mathrm{H}}\right)^{4}}}{8 c_{\mathrm{L}}^{3}} .
$$

$F^{*}\left(c_{\mathrm{L}}, c_{\mathrm{H}}\right)$ is the ratio of stage- 1 investments of the two types of contestants. It is directly proportional to heterogeneity in costs and continuation values, as equation (11) shows. Therefore, $F^{*}\left(c_{\mathrm{L}}, c_{\mathrm{H}}\right)$ can be interpreted as a measure for both the exogenous heterogeneity in investment costs between low cost and high cost contestants and the endogenous heterogeneity between types that is due to different continuation values in stage 1 . Using this expression we can redefine the probability that a low cost contestant wins as

$$
q_{L}^{*}=\frac{x_{1 \mathrm{~L}}^{*}}{x_{1 \mathrm{~L}}^{*}+x_{1 \mathrm{H}}^{*}}=\frac{F^{*}}{1+F^{*}}=\frac{\left(c_{\mathrm{H}}-c_{\mathrm{L}}\right)\left(c_{\mathrm{L}}+c_{\mathrm{H}}\right)^{2}+\sqrt{64 c_{\mathrm{H}}^{3} c_{\mathrm{L}}^{3}+\left(c_{\mathrm{L}}-c_{\mathrm{H}}\right)^{2}\left(c_{\mathrm{L}}+c_{\mathrm{H}}\right)^{4}}}{\left(c_{\mathrm{H}}-c_{\mathrm{L}}\right)\left(c_{\mathrm{L}}+c_{\mathrm{H}}\right)^{2}+\sqrt{64 c_{\mathrm{H}}^{3} c_{\mathrm{L}}^{3}+\left(c_{\mathrm{L}}-c_{\mathrm{H}}\right)^{2}\left(c_{\mathrm{L}}+c_{\mathrm{H}}\right)^{4}}+8 c_{\mathrm{L}}^{3}} .
$$

The expression $F^{*}\left(c_{\mathrm{L}}, c_{\mathrm{H}}\right)$ allows us to disentangle and solve analytically the two interdependent stage-1 interactions. We start by considering the continuation values which satisfy

$$
\begin{aligned}
& C V_{i}\left(x_{1 \mathrm{~L}}^{*}, x_{1 \mathrm{H}}^{*}\right)=C V_{k}\left(x_{1 \mathrm{~L}}^{*}, x_{1 \mathrm{H}}^{*}\right)=\frac{\left(c_{\mathrm{L}}+c_{\mathrm{H}}\right)^{2} F^{*}\left(c_{\mathrm{L}}, c_{\mathrm{H}}\right)+4 c_{\mathrm{H}}^{2}}{4\left(c_{\mathrm{L}}+c_{\mathrm{H}}\right)^{2}\left[1+F^{*}\left(c_{\mathrm{L}}, c_{\mathrm{H}}\right)\right]} R, \\
& C V_{j}\left(x_{1 \mathrm{~L}}^{*}, x_{1 \mathrm{H}}^{*}\right)=C V_{l}\left(x_{1 \mathrm{~L}}^{*}, x_{1 \mathrm{H}}^{*}\right)=\frac{\left(c_{\mathrm{L}}+c_{\mathrm{H}}\right)^{2}+4 c_{\mathrm{L}}^{2} F^{*}\left(c_{\mathrm{L}}, c_{\mathrm{H}}\right)}{4\left(c_{\mathrm{L}}+c_{\mathrm{H}}\right)^{2}\left[1+F^{*}\left(c_{\mathrm{L}}, c_{\mathrm{H}}\right)\right]} R .
\end{aligned}
$$

Note that $C V_{i}\left(x_{1 \mathrm{~L}}^{*}, x_{1 \mathrm{H}}^{*}\right)=C V_{k}\left(x_{1 \mathrm{~L}}^{*}, x_{1 \mathrm{H}}^{*}\right)$ and $C V_{j}\left(x_{1 \mathrm{~L}}^{*}, x_{1 \mathrm{H}}^{*}\right)=C V_{l}\left(x_{1 \mathrm{~L}}^{*}, x_{1 \mathrm{H}}^{*}\right)$ due to symmetry. Given these continuation values, stage 1 equilibrium efforts can be determined as

$$
\begin{aligned}
& x_{1 \mathrm{~L}}^{*}(\mathrm{LHLH}) \equiv x_{1 i}^{*}(\mathrm{LHLH})=x_{1 k}^{*}(\mathrm{LHLH})=\frac{\left(c_{\mathrm{L}}+c_{\mathrm{H}}\right)^{2} F^{*}\left(c_{\mathrm{L}}, c_{\mathrm{H}}\right)^{2}+4 c_{\mathrm{H}}^{2} F^{*}\left(c_{\mathrm{L}}, c_{\mathrm{H}}\right)}{4 c_{\mathrm{L}}\left(c_{\mathrm{L}}+c_{\mathrm{H}}\right)^{2}\left[1+F^{*}\left(c_{\mathrm{L}}, c_{\mathrm{H}}\right)\right]^{3}} P \\
& x_{1 \mathrm{H}}^{*}(\mathrm{LHLH}) \equiv x_{1 j}^{*}(\mathrm{LHLH})=x_{1 l}^{*}(\mathrm{LHLH})=\frac{\left(c_{\mathrm{L}}+c_{\mathrm{H}}\right)^{2} F^{*}\left(c_{\mathrm{L}}, c_{\mathrm{H}}\right)+4 c_{\mathrm{L}}^{2} F^{*}\left(c_{\mathrm{L}}, c_{\mathrm{H}}\right)^{2}}{4 c_{\mathrm{H}}\left(c_{\mathrm{L}}+c_{\mathrm{H}}\right)^{2}\left[1+F^{*}\left(c_{\mathrm{L}}, c_{\mathrm{H}}\right)\right]^{3}} P .
\end{aligned}
$$

\section{B Proofs}

\section{Prerequisites}

For the proofs for propositions 2 and 3 we need the following lemmata. In the derivation, we assume without loss of generality that $c_{\mathrm{H}} \geq c_{\mathrm{L}}=1$.

Lemma 1. Define $f\left(c_{H}\right)=\frac{5 c_{H}^{3}+2 c_{H}^{2}+c_{H}}{c_{H}^{2}+2 c_{H}+5}$. Then, the relation $F^{*}\left(1, c_{H}\right)>f\left(c_{H}\right)$ does hold for all $c_{H}>1$. Furthermore, for $c_{H}=1$ it holds that $F^{*}\left(1, c_{H}\right)=f\left(c_{H}\right)$.

Proof. From 11 we know that $\frac{x_{1 i}}{x_{1 j}}=\frac{c_{\mathrm{H}}}{c_{\mathrm{L}}} \frac{C V_{i}\left(x_{1 k}, x_{1 l}\right)}{C V_{j}\left(x_{1 k}, x_{1 l}\right)}$. Further $\frac{x_{1 i}^{*}}{x_{1 j}^{*}}=F^{*}\left(c_{\mathrm{L}}, c_{\mathrm{H}}\right)$. Consequently, using the assumption that $c_{\mathrm{H}} \geq c_{\mathrm{L}}=1$, it must hold that

$$
F^{*}\left(1, c_{\mathrm{H}}\right)=c_{\mathrm{H}} \frac{C V_{i}\left(x_{1 k}, x_{1 l}\right)}{C V_{j}\left(x_{1 k}, x_{1 l}\right)}=\frac{4 c_{\mathrm{H}}^{3}+c_{\mathrm{H}}\left(1+c_{\mathrm{H}}\right)^{2} \frac{x_{1 k}}{x_{1 l}}}{\left(1+c_{\mathrm{H}}\right)^{2}+4 \frac{x_{1 k}}{x_{1 l}}}
$$


Note that for $c_{\mathrm{H}}>1$, we have

$$
\frac{\partial F^{*}\left(1, c_{\mathrm{H}}\right)}{\partial \frac{x_{1 k}}{x_{1 l}}}=\frac{\left(1+c_{\mathrm{H}}\right)^{4}-16 c_{\mathrm{H}}^{2}}{\left[\left(1+c_{\mathrm{H}}\right)^{2}+4 \frac{x_{1 k}}{x_{1 l}}\right]^{2}}>0 .
$$

Further, recall that player 1 has both higher cost $\left(c_{\mathrm{H}}>1\right)$ and a lower continuation value $\left(C V_{k}>C V_{l}\right)$, such that $x_{1 k}>x_{1 l}$ does hold. Therefore, assuming $x_{1 k}=x_{1 l}$ underestimates $F^{*}\left(1, c_{\mathrm{H}}\right)$. Since

$$
f\left(c_{\mathrm{H}}\right)=\frac{5 c_{\mathrm{H}}^{3}+2 c_{\mathrm{H}}^{2}+c_{\mathrm{H}}}{c_{\mathrm{H}}^{2}+2 c_{\mathrm{H}}+5}
$$

is the expression we derive from $F^{*}\left(1, c_{\mathrm{H}}\right)$ under this assumption, we have proven $F^{*}\left(1, c_{\mathrm{H}}\right)>$ $f\left(c_{\mathrm{H}}\right)$. If we assume $c_{\mathrm{H}}=1$, all players are perfectly symmetric, such that $x_{1 k}=x_{1 l}$ does hold. Consequently, the relation $F^{*}\left(1, c_{\mathrm{H}}\right)=f\left(c_{\mathrm{H}}\right)$ does hold for $c_{\mathrm{H}}=1$.

Lemma 2. Define $f^{l}\left(c_{H}\right)=2 c_{H}-1$. Then, the relation $F^{*}\left(1, c_{H}\right)>f^{l}\left(c_{H}\right)$ does hold for all $c_{H}>1$. Furthermore, for $c_{H}=1$, it holds that $f\left(c_{H}\right)=f^{l}\left(c_{H}\right)$.

Proof. We start with the relation that we want to prove, namely:

$$
\begin{aligned}
f\left(c_{\mathrm{H}}\right) & >f^{l}\left(c_{\mathrm{H}}\right) \\
\Leftrightarrow 5 c_{\mathrm{H}}^{3}+2 c_{\mathrm{H}}^{2}+c_{\mathrm{H}} & >\left(2 c_{\mathrm{H}}-1\right)\left(c_{\mathrm{H}}^{2}+2 c_{\mathrm{H}}+5\right) \\
\Leftrightarrow 3 c_{\mathrm{H}}^{3}-c_{\mathrm{H}}^{2}-7 c_{\mathrm{H}}+5 & >0
\end{aligned}
$$

We now have to prove that $\phi\left(c_{\mathrm{H}}\right) \equiv 3 c_{\mathrm{H}}^{3}-c_{\mathrm{H}}^{2}-7 c_{\mathrm{H}}+5>0$ does always hold for $c_{\mathrm{H}}>1$. To see this, note that $\phi(\cdot)$ is a cubic function that has a local minimum at $c_{\mathrm{H}}=1$, and a local maximum at $c_{\mathrm{H}}=-7 / 9$. Furthermore, $\phi(1)=0$, which implies that $\phi\left(c_{\mathrm{H}}\right)>0$ for all $c_{\mathrm{H}}>1$.

Lemma 3. Assume without loss of generality that $c_{H} \geq c_{L}=1$ and define $f_{\mathrm{h}}\left(c_{H}\right)=\frac{c_{H}^{3}+2 c_{H}^{2}+c_{H}}{4}$. Then, the relation $F^{*}\left(1, c_{H}\right)<f^{h}\left(c_{H}\right)$ does hold for all $c_{H}>1$. Furthermore, for $c_{H}=1$, it holds that $F^{*}\left(1, c_{H}\right)=f^{h}\left(c_{H}\right)$.

Proof. From equation (11), we know that $\frac{x_{1 i}}{x_{1 j}}=\frac{c_{\mathrm{H}}}{c_{\mathrm{L}}} \frac{C V_{i}\left(x_{1 k}, x_{1 l}\right)}{C V_{j}\left(x_{1 k}, x_{1 l}\right)}$. Further, equation (13) tells us that $\frac{x_{1 i}^{*}}{x_{1 j}^{*}}=F^{*}\left(c_{\mathrm{L}}, c_{\mathrm{H}}\right)$. Consequently, using the assumption that $c_{\mathrm{H}} \geq c_{\mathrm{L}}=1$, it must hold that

$$
F^{*}\left(1, c_{\mathrm{H}}\right)=c_{\mathrm{H}} \frac{C V_{i}\left(x_{1 k}, x_{1 l}\right)}{C V_{j}\left(x_{1 k}, x_{1 l}\right)}=\frac{4 c_{\mathrm{H}}^{3} \times \frac{x_{1 l}}{x_{1 k}}+c_{\mathrm{H}}\left(1+c_{\mathrm{H}}\right)^{2}}{\left(1+c_{\mathrm{H}}\right)^{2} \times \frac{x_{1 l}}{x_{1 k}}+4} .
$$

Note that for $c_{\mathrm{H}}>1$, we have

$$
\frac{\partial F^{*}\left(1, c_{\mathrm{H}}\right)}{\partial \frac{x_{1 l}}{x_{1 k}}}=-\frac{\left(c_{\mathrm{H}}-1\right)^{2} c_{\mathrm{H}}\left(c_{\mathrm{H}}^{2}+6 c_{\mathrm{H}}+1\right)}{\left[\left(1+c_{\mathrm{H}}\right)^{2} \times \frac{x_{1 l}}{x_{1 k}}+4\right]^{2}}<0 .
$$

Further, recall that player 1 will never drop out in a pairwise competition for any finite degree of heterogeneity in terms of costs and continuation value, such that $x_{1 l}>0$ does hold. Therefore, assuming $x_{1 l}=0$ (which implies $\frac{x_{1 l}}{x_{1 k}}=0$ ) overestimates $F^{*}\left(1, c_{\mathrm{H}}\right)$, since this expression is decreasing in $\frac{x_{1 l}}{x_{1 k}}$. Since

$$
f^{h}\left(c_{\mathrm{H}}\right)=\frac{c_{\mathrm{H}}^{3}+2 c_{\mathrm{H}}^{2}+c_{\mathrm{H}}}{4}
$$

is the expression we derive from $F^{*}\left(1, c_{\mathrm{H}}\right)$ under this assumption, we have proven $F^{*}\left(1, c_{\mathrm{H}}\right)<$ $f^{h}\left(c_{\mathrm{H}}\right)$. If we assume $c_{\mathrm{H}}=1$, all players are perfectly symmetric, such that $x_{1 l}=x_{1 k}$ does 
hold. When inserting this relation in $F^{*}\left(1, c_{\mathrm{H}}\right)$, we see that the relation $F^{*}\left(1, c_{\mathrm{H}}\right)=f^{h}\left(c_{\mathrm{H}}\right)$ does hold for $c_{\mathrm{H}}=1$.

\section{Proof of Proposition 1}

In settings LLLL and HHHH total expenditures are independent from unit costs thus the rentdissipation rate is the same in both homogenous interactions. To show that consider the dissipation rate for each stage of these settings when $c_{i}=c_{j}>0$ and $T \in\{$ LLLL, HHHH $\}$.

$$
D R_{1}(T)=\frac{1}{R}\left(4 \cdot x_{1 i}^{*}\right) \cdot c_{i}
$$

Inserting the expressions for equilibrium efforts gives

$$
D R_{1}(T)=\frac{1}{R}\left(4 \cdot \frac{R}{16 c_{i}}\right) \cdot c_{i}
$$

And simplifying yields

$$
D R_{1}(T)=0.25
$$

The same can be shown for stage 2 of the homogenous settings:

$$
\begin{aligned}
D R_{2}(T) & =\frac{1}{R}\left(2 \cdot x_{2 i}^{*}\right) \cdot c_{i} \\
D R_{2}(T) & =\frac{1}{R}\left(2 \cdot \frac{R}{4 c_{i}}\right) \cdot c_{i} \\
D R_{2}(T) & =0.5
\end{aligned}
$$

Thus, the total rent-dissipation rate across all stages of the homogenous settings is $D R(T)=$ 0.75 with $T \in\{$ LLLL, HHHH $\}$.

\section{Proof of Proposition 2}

We have to show that the following relations hold

(a) $D R(\mathrm{HOM})>\left.D R(\mathrm{LLHH})\right|_{c_{H}>c_{L}}$

(b) $D R(\mathrm{HOM})>\left.D R(\mathrm{LHLH})\right|_{c_{H}>c_{L}}$

Consider first part (a). Here the stage 2 interaction in the heterogenous setting is for sure between a low cost and a high cost type, thus the rent-dissipation rate in equilibrium reads as follows:

$$
D R(\mathrm{LLHH})=\frac{1}{R}\left[\left(2 x_{1 \mathrm{~L}}^{*} \cdot c_{\mathrm{L}}+2 x_{1 \mathrm{H}}^{*} \cdot c_{\mathrm{H}}\right)+\left(x_{2 \mathrm{~L}}^{*} \cdot c_{\mathrm{L}}+x_{2 \mathrm{H}}^{*} \cdot c_{\mathrm{H}}\right)\right]
$$

Without loss of generality we can set $c_{\mathrm{L}}=1$. By inserting equilibrium efforts from (4) and (10) and simplifying we get

$$
D R(\text { LLHH })=\frac{\left(4 c_{\mathrm{H}}+c_{\mathrm{H}}^{2}+1\right)}{2\left(1+c_{\mathrm{H}}\right)^{2}}
$$

This is a quadratic expression in $c_{\mathrm{H}}$ with its maximum at $c_{\mathrm{H}}=1$ which would represent the homogenous setting where $c_{\mathrm{H}}=c_{\mathrm{L}}=1$. Thus, rent-dissipation rates are always smaller 
whenever $c_{\mathrm{H}}>c_{\mathrm{L}}=1$.

For part (b) we have to show that the rent-dissipation rate of the second heterogenous setting LHLH is again smaller than in the homogenous settings. We will proceed in two steps. First, we derive a necessary and sufficient condition in terms of the function $F^{*}\left(1, c_{\mathrm{H}}\right)$ for the relation $D R(\mathrm{LLHH})>D R(\mathrm{LHLH})$ to hold. Second, we prove that the equilibrium function $F^{*}\left(1, c_{\mathrm{H}}\right)$, which was derived in (13) indeed satisfies this condition. We start with the relation which we want to prove:

$$
D R(\mathrm{LLHH})>D R(\mathrm{LHLH})
$$

where $D R($ LLHH) is defined as in (17) and

$D R(\mathrm{LHLH})=\frac{1}{R}\left[2\left(q_{\mathrm{L}}^{2} \cdot x_{2 \mathrm{~L}}(\mathrm{LL}) c_{\mathrm{L}}+\left(1-q_{\mathrm{L}}\right)^{2} \cdot x_{2 \mathrm{H}}(\mathrm{HH}) c_{\mathrm{H}}+q_{\mathrm{L}}\left(1-q_{\mathrm{L}}\right) \cdot\left(x_{2 \mathrm{~L}}(\mathrm{LH}) c_{\mathrm{L}}+x_{2 \mathrm{H}}(\mathrm{LH}) c_{\mathrm{H}}\right)\right)\right]$

Inserting equilibrium expressions and simplifying yields

$\frac{c_{\mathrm{H}}^{2}+4 c_{\mathrm{H}}+1}{2\left(c_{\mathrm{H}}+1\right)^{2}}>\frac{\left(4 c_{\mathrm{H}}^{3}+c_{\mathrm{H}}^{2}+2 c_{\mathrm{H}}\right)+\left(c_{\mathrm{H}}+1\right)^{2} F^{*}\left(1, c_{\mathrm{H}}\right)^{3}+\left(2 c_{\mathrm{H}}^{2}+12 c_{\mathrm{H}}+2\right) F^{*}\left(1, c_{\mathrm{H}}\right)^{2}+\left(c_{\mathrm{H}}^{3}+7 c_{\mathrm{H}}^{2}+11 c_{\mathrm{H}}\right) F^{*}\left(1, c_{\mathrm{H}}\right)+F^{*}\left(1, c_{\mathrm{H}}\right)+1}{2\left(c_{\mathrm{H}}+1\right)^{2}\left(1+F^{*}\left(1, c_{\mathrm{H}}\right)\right)^{3}}$

Multiplying both sides by $2\left(c_{\mathrm{H}}+1\right)^{2}\left(1+F^{*}\left(1, c_{\mathrm{H}}\right)\right)^{3}$ and rearranging gives

$$
F^{*}\left(1, c_{\mathrm{H}}\right)^{3} \cdot 2 c_{\mathrm{H}}+F^{*}\left(1, c_{\mathrm{H}}\right)^{2} \cdot\left(c_{\mathrm{H}}^{2}+1\right)+F^{*}\left(1, c_{\mathrm{H}}\right) \cdot\left(-c_{\mathrm{H}}^{3}-4 c_{\mathrm{H}}^{2}+c_{\mathrm{H}}+2\right)+2 c_{\mathrm{H}}-4 c_{\mathrm{H}}^{3}>0 .
$$

Solving for $F^{*}\left(1, c_{\mathrm{H}}\right)$ gives us following roots:

$$
\begin{aligned}
& r_{1}=\frac{-1+c_{\mathrm{H}}^{2}-\sqrt{1-16 c_{\mathrm{H}}-2 c_{\mathrm{H}}^{2}+32 c_{\mathrm{H}}^{3}+c_{\mathrm{H}}^{4}}}{4 c_{\mathrm{H}}} \\
& r_{2}=\frac{-1+c_{\mathrm{H}}^{2}+\sqrt{1-16 c_{\mathrm{H}}-2 c_{\mathrm{H}}^{2}+32 c_{\mathrm{H}}^{3}+c_{\mathrm{H}}^{4}}}{4 c_{\mathrm{H}}} \\
& r_{3}=-c_{\mathrm{H}}
\end{aligned}
$$

We do only have to consider $r_{2}$, since $r_{1}$ and $r_{3}$ are below 0 for some values of $c_{\mathrm{H}}$, while $F^{*}\left(1, c_{\mathrm{H}}\right) \geq 1$ for all $c_{\mathrm{H}} \geq 12$ Thus we have to show that

$$
F^{*}\left(1, c_{\mathrm{H}}\right)>r_{2} \equiv \frac{-1+c_{\mathrm{H}}^{2}+\sqrt{1-16 c_{\mathrm{H}}-2 c_{\mathrm{H}}^{2}+32 c_{\mathrm{H}}^{3}+c_{\mathrm{H}}^{4}}}{4 c_{\mathrm{H}}},
$$

for all $c_{\mathrm{H}}>1$. From Lemmata 1 and 2 we know that $F^{*}\left(1, c_{\mathrm{H}}\right)>f^{l}\left(c_{\mathrm{H}}\right)$. Consequently, a sufficient condition for $(19)$ is given by $f^{l}\left(c_{\mathrm{H}}\right)>r_{2}$. Using the expression $f^{l}\left(c_{\mathrm{H}}\right)$ and rearranging gives

$$
7 c_{\mathrm{H}}^{2}-4 c_{\mathrm{H}}+1>\sqrt{1-16 c_{\mathrm{H}}-2 c_{\mathrm{H}}^{2}+32 c_{\mathrm{H}}^{3}+c_{\mathrm{H}}^{4}} .
$$

Squaring both sides leaves us with 23

$$
2 c_{\mathrm{H}}\left(25 c_{\mathrm{H}}^{3}-12 c_{\mathrm{H}}^{2}+14 c_{\mathrm{H}}-12\right)>0
$$

This relation is always satisfied if $c_{\mathrm{H}}>1$, which completes the proof.

\footnotetext{
${ }^{22}$ It followes from Lemma 1 that $\frac{\partial F^{*}\left(1, c_{\mathrm{H}}\right)}{\partial c_{\mathrm{H}}}>0$, and $F^{*}(1,1)=1$ holds. Therefore, $F^{*}\left(1, c_{\mathrm{H}}\right) \geq 1$ for all $c_{\mathrm{H}} \geq 1$.

${ }^{23}$ Note that squaring is without loss of generality here, since we are only interested in solutions for $c_{\mathrm{H}}>1$.
} 
We proved the relation $D R(\mathrm{LLHH})>D R(\mathrm{LHLH})$ and from part (a) of the proof of Proposition 2 we know $D R$ (hom) $>D R(\mathrm{LLHH})$ thus $D R($ hom $)>D R(\mathrm{LHLH})$ is also true.

\section{Proof of Proposition 3}

We want to show that following relations hold

$$
\begin{aligned}
& \text { (a) } D R_{1} \text { (LHLH) }<D R_{1}(\mathrm{LLHH}) \forall c_{H}>c_{L} \\
& \text { (b) } D R_{2} \text { (LHLH) }>D R_{2}(\mathrm{LLHH}) \forall c_{H}>c_{L}
\end{aligned}
$$

\section{Dissipation Rates in Stage 1}

To prove that aggregate effort in the semifinal is higher in seeding LLHH than in seeding LHLH we start with the relation we want to prove where we use the fact that $x_{1 \mathrm{~L}}^{*}(\mathrm{LHLH})=$ $x_{1 \mathrm{H}}^{*}(\mathrm{LHLH}) \cdot F^{*}$.

$$
\begin{aligned}
D R_{1}(\mathrm{LLHH}) & >D R_{1}(\mathrm{LHLH}) \\
2\left[x_{1 \mathrm{~L}}^{*}(\mathrm{LLHH}) \cdot c_{\mathrm{L}}+x_{1 \mathrm{H}}^{*}(\mathrm{LLHH}) \cdot c_{\mathrm{H}}\right) & >2\left(x_{1 \mathrm{H}}^{*}(\mathrm{LHLH}) F^{*} \cdot c_{\mathrm{L}}+x_{1 \mathrm{H}}^{*}(\mathrm{LHLH}) \cdot c_{\mathrm{H}}\right)
\end{aligned}
$$

Inserting equilibrium values and simplifying gives

$$
\frac{c_{\mathrm{H}}^{2}+1}{2\left(c_{\mathrm{H}}+1\right)^{2}}-\frac{F^{*}\left(c_{\mathrm{H}}+F^{*}\right)\left(\left(c_{\mathrm{H}}+1\right)^{2}+4 F^{*}\right)}{2 c_{\mathrm{H}}\left(c_{\mathrm{H}}+1\right)^{2}\left(F^{*}+1\right)^{3}}>0
$$

Recall from the derivation of equilibrium investments in Appendix A that the formal expressions are fairly complicated, in particular due to the $F^{*}\left(1, c_{\mathrm{H}}\right)$-function. To simplify the subsequent analysis, we will therefore make use of Lemma 3 and replace $F^{*}\left(1, c_{\mathrm{H}}\right)$ by $f^{h}\left(c_{\mathrm{H}}\right)=\frac{c_{\mathrm{H}}^{3}+2 c_{\mathrm{H}}^{2}+c_{\mathrm{H}}}{4}$.

Since $F^{*}\left(1, c_{\mathrm{H}}\right)<f^{h}\left(c_{\mathrm{H}}\right)$ we overestimate the rent-dissipation rate in setting LHLH by using $f^{h}$.

Inserting $f^{h}\left(c_{\mathrm{H}}\right)$ in 20 and simplifying leaves us with the sufficient condition

$$
\frac{\left(c_{\mathrm{H}}-1\right)^{2}\left(c_{\mathrm{H}}+2\right)\left(c_{\mathrm{H}}^{2}+c_{\mathrm{H}}+2\right)\left(c_{\mathrm{H}}\left(c_{\mathrm{H}}+1\right)\left(c_{\mathrm{H}}\left(c_{\mathrm{H}}\left(c_{\mathrm{H}}\left(c_{\mathrm{H}}+4\right)+8\right)+20\right)+23\right)+16\right)}{2\left(c_{\mathrm{H}}+1\right)^{2}\left(c_{\mathrm{H}}\left(c_{\mathrm{H}}+1\right)^{2}+4\right)^{3}}>0
$$

which is always fullfilled under the condition $c_{\mathrm{H}}>c_{\mathrm{L}}=1$.

\section{Dissipation Rates in Stage 2}

We start again with the condition we want to prove.

$$
\begin{aligned}
D R_{2}(\mathrm{LLHH}) & <D R_{2}(\mathrm{LHLH}) \\
x_{2 \mathrm{~L}}^{*}(\mathrm{LH}) c_{\mathrm{L}}+x_{2 \mathrm{H}}^{*}(\mathrm{LH}) c_{\mathrm{H}} & <2\left\{q_{\mathrm{L}}^{2} x_{2 \mathrm{~L}}^{*}(\mathrm{LL}) c_{\mathrm{L}}+\left(1-q_{\mathrm{L}}\right)^{2} x_{2 \mathrm{H}}^{*}(\mathrm{HH}) c_{\mathrm{H}}+q_{\mathrm{L}}\left(1-q_{\mathrm{L}}\right)\left[x_{2 \mathrm{~L}}^{*}(\mathrm{LH}) c_{\mathrm{L}}+x_{2 \mathrm{H}}^{*}(\mathrm{LH}) c_{\mathrm{H}}\right]\right\}
\end{aligned}
$$

Inserting equilibrium values and using the fact that we can rewrite the probability that a low cost contestant wins in the stage- 1 interaction as $q_{\mathrm{L}}=\frac{F^{*}}{1+F^{*}}($ see (14) $)$ and simplifying yields

$$
\frac{2 c_{\mathrm{H}}}{\left(1+c_{\mathrm{H}}\right)^{2}}<\frac{\left(c_{\mathrm{H}}+1\right)^{2} F\left(1, c_{\mathrm{H}}\right)^{2}+8 c_{\mathrm{H}} F\left(1, c_{\mathrm{H}}\right)+\left(1+c_{\mathrm{H}}\right)^{2}}{2\left(c_{\mathrm{H}}+1\right)^{2}\left(F\left(1, c_{\mathrm{H}}\right)+1\right)^{2}}
$$


Multiplying both sides by $2\left(1+c_{\mathrm{H}}\right)^{2}\left(F\left(1, c_{\mathrm{H}}\right)+1\right)^{2}$ and rearranging gives

$$
\left(c_{\mathrm{H}}-1\right)^{2}\left(F\left(1, c_{\mathrm{H}}\right)^{2}+1\right)>0
$$

Inserting the expression for $F^{*}\left(1, c_{\mathrm{H}}\right)$ gives the relation

$$
\left(c_{\mathrm{H}}-1\right)^{2}\left(\frac{1}{64}\left(\left(c_{\mathrm{H}}-1\right)\left(1+c_{\mathrm{H}}\right)^{2}+\sqrt{64 c_{\mathrm{H}}^{3}+\left(1-c_{\mathrm{H}}\right)^{2}\left(1+c_{\mathrm{H}}\right)^{4}}\right)^{2}+1\right)>0
$$

which is fulfilled under the condition that $c_{\mathrm{H}}>c_{\mathrm{L}}=1$. 


\section{Experimental Instructions}

The experimental instructions consist of three parts: First, experimental subjects receive some general information about the experimental session. Then, they are informed about the main treatment (Experiment 1) with homogeneous or heterogeneous participants (both versions are provided). Finally, subjects receive instructions for the elicitation of risk attitudes (Experiment 2).

\section{WELCOME TO THIS EXPERIMENT AND THANK YOU FOR YOUR PARTICIPATION}

\section{General Instructions:}

You will participate in 2 different experiments today. Please stop talking to any other participant of this experiment from now on until the end of this session. In each of the two experiments, you will have to make certain decisions and may earn an appreciable amount of money. Your earnings will depend upon several factors: on your decisions, on the decisions of other participants, and on random components, i.e. chance. The following instructions explain how your earnings will be determined.

The experimental currency is denoted Taler. In addition to your Taler earnings in experiments 1 and 2, you receive 3 EURO show-up fee. You may increase your Taler earnings in experiments 1 and 2, where 2 Taler equal 1 Euro-Cent, i.e.

\section{Taler correspond to 1 Euro.}

At the end of this experimental session your Taler earnings will be converted into Euro and paid to you in cash.

Before the experimental session starts, you receive a card with your participant number. All your decisions in this experiment will be entered in a mask on the computer, the same holds for all other participants of the experiment. In addition, the computer will determine the random components which are needed in some of the experiments. All data collected in this experiment will be matched to your participant number, not to your name or student number. Your participant number will also be used for payment of your earnings at the end of the experimental session. Therefore, your decisions and the information provided in the experiments are completely anonymous; neither the experimenter nor anybody else can match these data to your identity.

We will start with experiment 1 , followed by experiment 2 . The instructions for experiment 2 will only be distributed right before this experiment starts, i.e. subsequent to experiment 1 .

You will receive your earnings in cash at the end of the experimental session. 


\section{Experiment 1 [Treatments LLLL and HHHH]}

Overall, there are 30 decision rounds with two stages each in Experiment 1 . The course of events is the same in each decision round. You will be randomly and anonymously placed into a group of four participants in each round, and the identity of participants in your group changes with each decision round.

\section{Course of events in an arbitrary decision round}

All four participants of each group receive an endowment of 240 Taler at the beginning of a decision round. The endowment can be used to buy a certain amount of balls in two subsequent stages of a decision round. It is important to note that you receive one endowment only which must suffice to buy balls in both stages. The costs for the purchase of a ball are the same for all participants: Participants have to pay XXX Taler for each ball they buy in stage 1 or stage 2, i.e.

\section{1 ball costs XXX Taler \\ 2 balls cost XXX Taler \\ (and so on)}

When deciding how many balls you want to buy, you do not know the decision of other participants. Also, your decision is not revealed to any other participant.

All interactions in the experiment are pair-wise. Assume that you are in one group with participant A, participant B, and participant $C$. Then, you interact with participant A in stage 1, while participants B and $C$ simultaneously meet each other in the second stage 1 interaction. If you reach stage 2 , you will interact either with participant B or C, depending on the outcome in the second stage 1 interaction. In stage 1, there are two ballot boxes:

- all balls bought by you or participant $\mathrm{A}$ are placed in ballot box 1

- $\quad$ all balls bought by participants B and C are placed in ballot box 2

One ball is randomly drawn from each ballot box, and each ball drawn with the same probability. The two participants whose balls are drawn from ballot box 1 and 2, respectively, reach stage 2; the decision round is over for the other two participants (whose balls were not drawn), i.e. they drop out from this decision round. Any participant has to pay the balls he or she bought in stage 1, whether or not he/she reached stage 2 . The respective amount is deducted from the endowment.

The two participants who reached stage 2 do again buy a certain number of balls, using whatever remains from the endowment they received after costs for balls in stage 1 were deducted. The balls are then placed into ballot box 3. One ball is randomly drawn from ballot box 3 . The participant whose ball is drawn receives a prize of $\mathbf{2 4 0}$ Taler. The other participants do not receive any prize in this decision round. Independent of whether or not a participant receives the prize, he/she does always have to pay for the balls bought in stage 2 .

Let's take a closer look at the random draw of balls from ballot boxes. Assume, for example, that all balls which you bought are green colored, and that you interact with participant A in stage 1. Then, the probability that one of your balls is drawn (such that you make it to stage 2) satisfies

$$
\text { probability }(\text { green ball is drawn })=\frac{\# \text { green balls }}{\# \text { green balls }+\# \text { balls by participant } \mathrm{A}}
$$

where \# is short for number. The same probability rule does also hold for other participants in your group. Consequently, the probability that one of your balls in drawn is higher

- the more balls you purchased

- the less balls the other participant with whom you interact purchased.

The random draw is simulated by the computer according to the procedures outlined above. If both participants of a pairing choose to buy zero balls, each participant wins with a probability of $50 \%$. 
STUFE 1

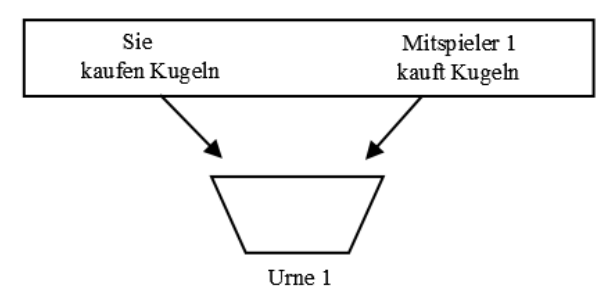

Eine Kugel (entweder eine von Ihren oder eine von Mitspieler 1) wird aus Urne 1 gezogen

Wenn eine Ihrer Kugeln gezogen wird, nehmen Sie an Stufe 2 teil; wenn nicht, nimmt Mitspieler 1 an Stufe 2 teil.

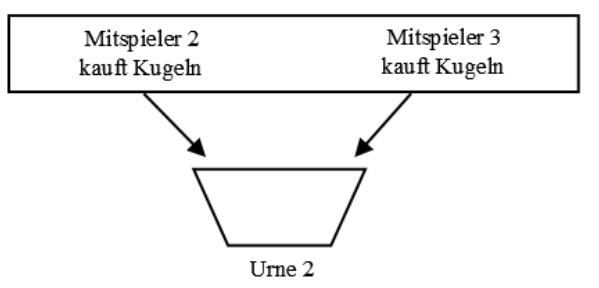

Eine Kugel (entweder eine von Mitspieler 2 oder eine von Mitspieler 3) wird aus Ume 2 gezogen.

Wenn eine Kugel von Mitspieler 2 gezogen wird, nimmt er an Stufe 2 teil; w enn nicht, nimmt Mitspieler 3 an Stufe 2 teil.

\section{STUFE 2}

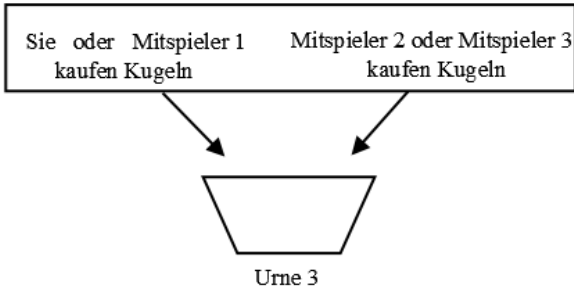

Eine Kugel wird aus Urne 3 gezogen. Der Spieler, dessen Kugel gezogen wurde, erhält einen Preis von 240 Taler.

\section{Your Payoff}

Assume that you bought "X1" balls in stage 1, and that you buy "X2" balls whenever you reach stage 2. Then, there are three possibilities for your payoff:

1) None of your balls is drawn in stage 1

$$
\begin{aligned}
\text { Your Payoff } & =\text { endowment } & -\mathrm{X} 1 * \mathrm{XXX} \text { Taler } \\
& =240 \text { Taler } & -\mathrm{X} 1 * \mathrm{XXX} \text { Taler }
\end{aligned}
$$

2) one of your balls is drawn from the ballot box in stage 1; in stage 2, none of your balls is drawn

$$
\begin{aligned}
\text { Your Payoff } & =\text { endowment } & -\mathrm{X} 1 * \mathrm{XXX} \text { Taler }-\mathrm{X} 2 * \mathrm{XXX} \text { Taler } \\
& =240 \text { Taler } & -\mathrm{X} 1 * \mathrm{XXX} \text { Taler }-\mathrm{X} 2 * \mathrm{XXX} \text { Taler }
\end{aligned}
$$

3) one of your balls is drawn from the ballot box in stage 1; also, one of your balls is drawn in stage 2

$$
\begin{aligned}
\text { Your Payoff } & =\text { endowment } & -\mathrm{X} 1 * \mathrm{XXX} \text { Taler }-\mathrm{X} 2 * \mathrm{XXX} \text { Taler }+ \text { prize } \\
& =240 \text { Taler } & -\mathrm{X} 1 * \mathrm{XXX} \text { Taler }-\mathrm{X} 2 * \mathrm{XXX} \text { Taler }+240 \text { Taler }
\end{aligned}
$$

Therefore, your payoff is determined by the following components: by the number of balls you buy in stage 1 ("X1"); by the number of balls you buy in stage 2 ("X2") if you reach it; by up to two random draws (one of your balls is drawn/not drawn in stage 1 and potentially stage 2). The same holds for any other participants of the experiment.

\section{Information:}

- After you made your decision in stage 1, you are informed whether or not you can participate in stage 2, i.e. whether or not one of your balls was drawn from ballot box 1 .

- If you did not reach stage 2, you are informed about how many balls participant A bought in stage 1. 
- If you reach stage 2, you receive information about the remaining endowment (after costs for the purchase in stage 1 are deducted.

- After you made your decision in stage 2, you learn whether or not one of your balls was drawn from ballot box 3 and how many balls the participants who you met in stages 1 and 2, respectively, bought. Further, you learn your payoff for the respective decision round.

Decision: In each of the 30 decision rounds you have to decide how many balls you want to buy in stage 1 . If you reach stage 2, you face a similar decision in stage 2 . In both cases, you have to enter a number into a field on the computer screen. An example of the decision screen in stage 1 is shown below.

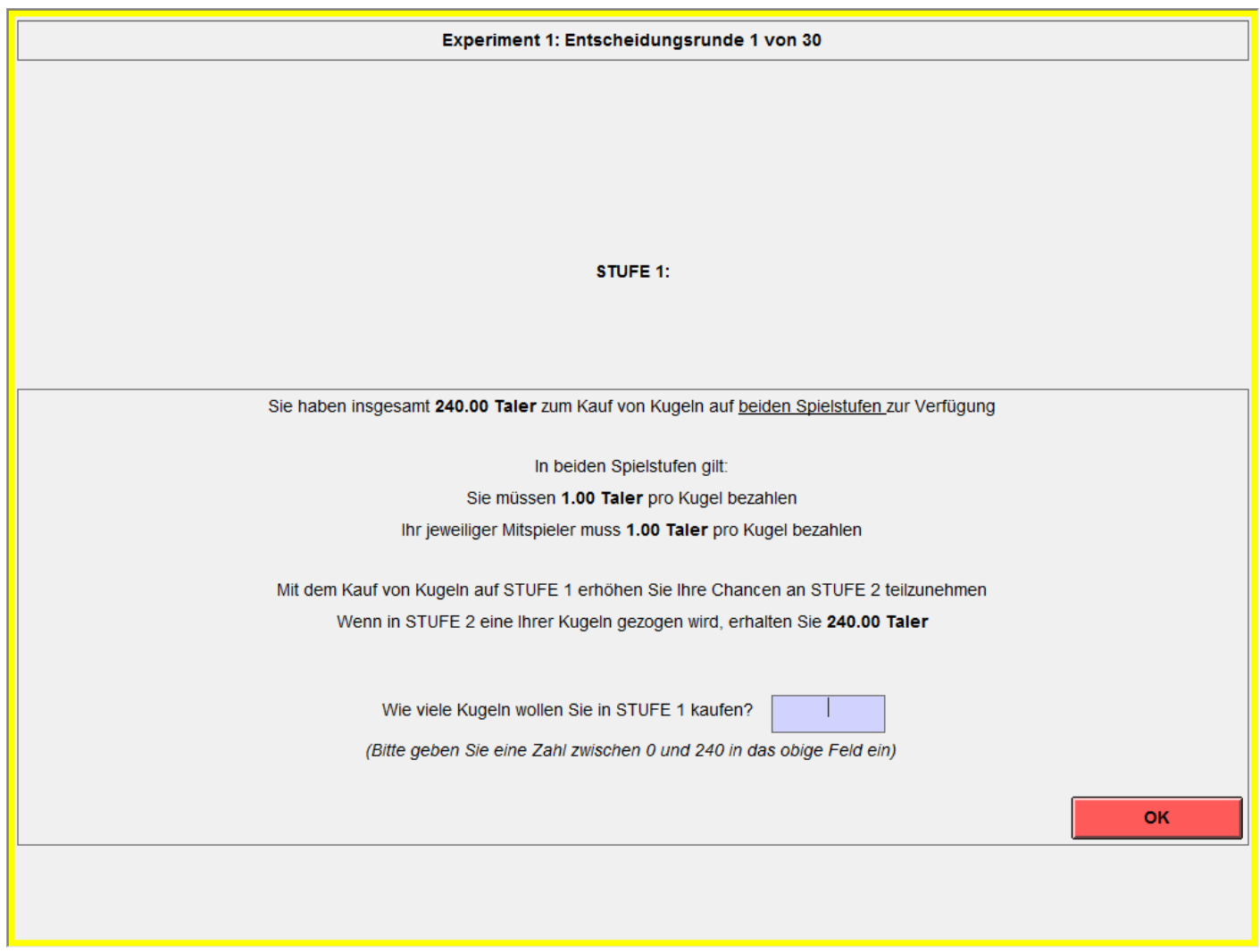

Your Total Payoff: Four out of 30 decision rounds are paid. These rounds are randomly determined, i.e., the probability that some decision round is paid is identical ex-ante for all 30 decision rounds. You will receive the sum of payoffs for the respective decision rounds.

\section{Remember:}

You receive an endowment of 240 Taler at the beginning of each decision round and have to decide how many balls you want to buy in stage 1; if you reach stage 2, you have to decide again. Overall, there are three additional participants in each group who face the same problem. The identity of these participants is randomly determined in each decision round. Every participant has to pay XXX Taler for each ball he/she buys in stage 1 or stage 2 .

If you have any questions, please raise your hand now! 


\section{Experiment 1 [Treatments LLHH and LHLH]}

Overall, there are 30 decision rounds with two stages each in Experiment 1 . The course of events is the same in each decision round. You will be randomly and anonymously placed into a group of four participants in each round, and the identity of participants in your group changes with each decision round.

\section{Course of events in an arbitrary decision round}

All four participants of each group receive an endowment of 240 Taler at the beginning of a decision round. The endowment can be used to buy a certain amount of balls in two subsequent stages of a decision round. It is important to note that you receive one endowment only which must suffice to buy balls in both stages. The costs for the purchase of a ball are not the same for all participants:

In each decision round, there are two participants with high costs (Type H), and two with low costs (Type L). You will be informed about your player type on the computer screen right before the start of Experiment 1. It holds both for you as well as for all other participants of this experiment that your player type does not change across decision rounds!

Participants with high costs (Type H) have to pay 1.50 Taler for each ball they buy on stage 1 or stage 2:

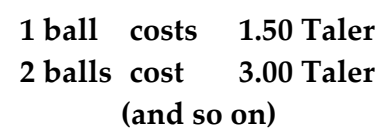

Participants with low costs (Type L) have to pay 1.00 Taler for each ball they buy on stage 1 or stage 2: i.e.

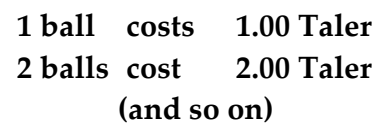

Apart from the aforementioned cost differences, there is no further difference between the two player types.

When deciding how many balls you want to buy, you do not know the decision of other participants. Also, your decision is not revealed to any other participant.

All interactions in the experiment are pair-wise. Assume that you are in one group with participant A, participant $B$, and participant $C$. Then, you interact with participant $A$ in stage 1 , while participants $B$ and $C$ simultaneously meet each other in the second stage 1 interaction. If you reach stage 2, you will interact either with participant B or C, depending on the outcome in the second stage 1 interaction. In stage 1, there are two ballot boxes:

- $\quad$ all balls bought by you or participant A are placed in ballot box 1

- $\quad$ all balls bought by participants B and C are placed in ballot box 2

One ball is randomly drawn from each ballot box, and each ball drawn with the same probability. The two participants whose balls are drawn from ballot box 1 and 2, respectively, reach stage 2; the decision round is over for the other two participants (whose balls were not drawn), i.e. they drop out from this decision round. Any participant has to pay the balls he or she bought in stage 1, whether or not he/she reached stage 2 . The respective amount is deducted from the endowment.

The two participants who reached stage 2 do again buy a certain number of balls, using whatever remains from the endowment they received after costs for balls in stage 1 were deducted. The balls are then placed into ballot box 3. One ball is randomly drawn from ballot box 3 . The participant whose ball is drawn receives a prize of $\mathbf{2 4 0}$ Taler. The other participants do not receive any prize in this decision round. Independent of whether or not a participant receives the prize, he/she does always have to pay for the balls bought in stage 2 . 
Let's take a closer look at the random draw of balls from ballot boxes. Assume, for example, that all balls which you bought are green colored, and that you interact with participant A in stage 1. Then, the probability that one of your balls is drawn (such that you make it to stage 2) satisfies

$$
\text { probability }(\text { green ball is drawn })=\frac{\# \text { green balls }}{\# \text { green balls }+\# \text { balls by participant } A}
$$

where \# is short for number. The same probability rule does also hold for other participants in your group. Consequently, the probability that one of your balls in drawn is higher

- the more balls you purchased

- the less balls the other participant with whom you interact purchased.

The random draw is simulated by the computer according to the procedures outlined above. If both participants of a pairing choose to buy zero balls, each participant wins with a probability of $50 \%$.

Jeder Spieler erhālt eine A nfangsausstattung von 240 Talern. Er muss damit alle von ihm in Stufe 1 und Stufe 2 gekauften Kugeln bezahlen.

\section{STUFE 1}

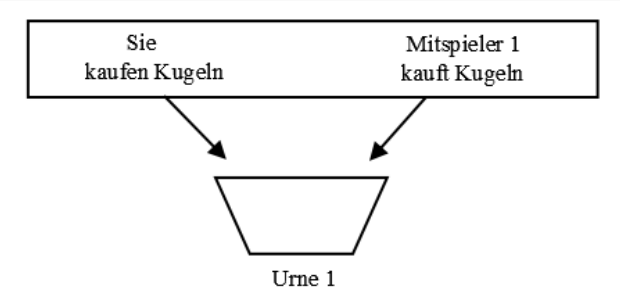

Eine Kugel (entweder eine von Ihren oder eine von Mitspieler 1) wird aus Urne 1 gezogen.

Wenn eine Ihrer Kugeln gezogen wird, nehmen Sie an Stufe 2 teil; wenn nicht, nimmt Mitspieler 1 an Stufe 2 teil.

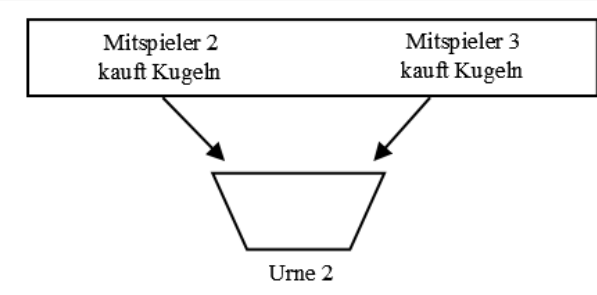

Eine Kugel (entweder eine von Mitspieler 2 oder eine von Mitspieler 3) wird aus Ume 2 gezogen.

Wenn eine Kugel von Mitspieler 2 gezogen wird, nimmt er an Stufe 2 teil; w enn nicht, nimmt Mitspieler 3 an Stufe 2 teil

\section{STUFE 2}

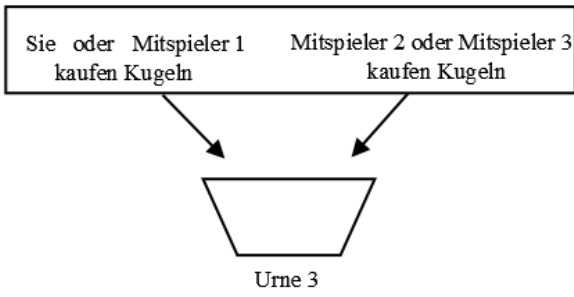

Eine Kugel wird aus Urne 3 gezogen. Der Spieler, dessen Kugel gezogen wurde, erhält einen Preis von $240 \mathrm{~T}$ aler.

\section{Your Payoff}

Assume that you bought "X1" balls in stage 1, and that you buy "X2" balls whenever you reach stage 2. Then, there are three possibilities for your payoff:

1) None of your balls is drawn in stage 1

$$
\begin{array}{rlrl}
\text { Your Payoff } & =\text { endowment } & -\mathrm{X} 1 * \text { your cost } / \text { ball } \\
& =240 \text { Taler } & & -\mathrm{X} 1 * \text { your cost } / \text { ball }
\end{array}
$$

2) one of your balls is drawn from the ballot box in stage 1; in stage 2, none of your balls is drawn

$$
\begin{aligned}
\text { Your Payof } \mathrm{f} & =\text { endowment } & -\mathrm{X} 1 * \text { your cost } / \mathrm{ball}-\mathrm{X} 2 * \text { your cost } / \mathrm{ball} \\
& =240 \text { Taler } & -\mathrm{X} 1 * \text { your cost } / \mathrm{ball}-\mathrm{X} 2 * \text { your cost } / \mathrm{ball}
\end{aligned}
$$


3) one of your balls is drawn from the ballot box in stage 1; also, one of your balls is drawn in stage 2

Your Payoff $=$ endowment $-\mathrm{X} 1 *$ your cost $/$ ball $-\mathrm{X} 2 *$ your cost $/ \mathrm{ball}+$ prize

$=240$ Taler $-\mathrm{X} 1 *$ your cost $/$ ball $-\mathrm{X} 2 *$ your cost $/$ ball +240 Taler

Therefore, your payoff is determined by the following components: by the number of balls you buy in stage 1 ("X1"); by the number of balls you buy in stage 2 ("X2") if you reach it; by your player type, i.e., by your cost per ball; by up to two random draws (one of your balls is drawn/not drawn in stage 1 and potentially stage 2). The same holds for any other participants of the experiment. Note, however, that the costs per ball differ across participants

Information: Prior to the first decision round, you are informed about your own type. Your type (your cost per ball) remain unchanged in all decision rounds.

- Before you make your first decision in stage 1, you are informed about the type of participant A, i.e., you know the type of your opponent.

- After you made your decision in stage 1, you are informed whether or not you can participate in stage 2, i.e. whether or not one of your balls was drawn from ballot box 1 .

- If you did not reach stage 2, you are informed about how many balls participant A bought in stage 1.

- If you reach stage 2, you receive information about the remaining endowment (after costs for the purchase in stage 1 are deducted), and you are informed about the type of your opponent in stage 2 .

- After you made your decision in stage 2, you learn whether or not one of your balls was drawn from ballot box 3 and how many balls the participants who you met in stages 1 and 2, respectively, bought. Further, you learn your payoff for the respective decision round.

Decision: In each of the 30 decision rounds you have to decide how many balls you want to buy in stage 1 . If you reach stage 2, you face a similar decision in stage 2. In both cases, you have to enter a number into a field on the computer screen. An example of the decision screen in stage 1 is shown below. [same picture as in instructions for homogeneous treatments]

Your Total Payoff: Four out of 30 decision rounds are paid. These rounds are randomly determined, i.e., the probability that some decision round is paid is identical ex-ante for all 30 decision rounds. You will receive the sum of payoffs for the respective decision rounds.

\section{Remember:}

You receive an endowment of 240 Taler at the beginning of each decision round and have to decide how many balls you want to buy in stage 1; if you reach stage 2, you have to decide again. Overall, there are three additional participants in each group who face the same problem. The identity of these participants is randomly determined in each decision round. Two participants are of Type $\mathrm{H}$ (cost per ball =1.50 Taler), and two participants are of Type $\mathrm{L}$ (cost per ball = 1.00 Taler).

If you have any questions, please raise your hand now! 


\section{Experiment 2}

In Experiment 2, you will face 21 decisions. Each decision is a choice between option 1 and option 2. Each choice affects you own payoff, but not the payoff of any other participant of the experiment. When choosing option 1, your payoff is affected by chance, while option 2 implies a certain payment. You may be asked, for example, whether you prefer option 1, in which you receive either 400 Taler or 0 Taler with a $50 \%$ chance, or if you rather like option 2 , which implies a sure payoff of c Taler. In the experiment, you will have to choose the option you prefer. This decision problem would be presented to you as follows:

\begin{tabular}{|c|c|c|c|}
\hline Option 1 & \multirow{2}{*}{$\begin{array}{c}\text { Option } 2 \\
\text { with certainty } c \text { Taler }\end{array}$} & \multicolumn{2}{|c|}{ Your Choice } \\
\hline $\begin{array}{lr}\text { with } 50 \% \text { probability } & 400 \text { Taler } \\
\text { with } 50 \% \text { probability } & 0 \text { Taler }\end{array}$ & & Option $1 \bigcirc$ & Option 2 \\
\hline
\end{tabular}

As previously mentioned, you will encounter 21 decision problems of this kind. Your payoff from Experiment 2 is determined as follows:

At the end of all experiments, one of the 21 decision problems will be randomly chosen for each experimental participant. The option you chose in this decision problem determines your payoff. Assume, for example, that the previous example is chosen for you, and that you preferred option 1 over option 2 . Then, you would receive 400 Taler or 0 Taler, each with a probability of $50 \%$. Whether you receive 400 Taler or 0 Taler is determined by a simulated random draw of the computer. 
University of Innsbruck - Working Papers in Economics and Statistics Recent Papers can be accessed on the following webpage:

http://eeecon.uibk.ac.at/wopec/

2013-29 Tanja Hörtnagl, Rudolf Kerschbamer, Rudi Stracke, Uwe Sunde: Heterogeneity in rent-seeking contests with multiple stages: Theory and experimental evidence

2013-28 Dominik Erharter: Promoting coordination in summary-statistic games

2013-27 Dominik Erharter: Screening experts' distributional preferences

2013-26 Loukas Balafoutas, Rudolf Kerschbamer, Matthias Sutter: Seconddegree moral hazard in a real-world credence goods market

2013-25 Rudolf Kerschbamer: The geometry of distributional preferences and a nonparametric identification approach

2013-24 Nadja Klein, Michel Denuit, Stefan Lang, Thomas Kneib: Nonlife ratemaking and risk management with bayesian additive models for location, scale and shape

2013-23 Nadja Klein, Thomas Kneib, Stefan Lang: Bayesian structured additive distributional regression

2013-22 David Plavcan, Georg J. Mayr, Achim Zeileis: Automatic and probabilistic foehn diagnosis with a statistical mixture model

2013-21 Jakob W. Messner, Georg J. Mayr, Achim Zeileis, Daniel S. Wilks: Extending extended logistic regression to effectively utilize the ensemble spread

2013-20 Michael Greinecker, Konrad Podczeck: Liapounoff's vector measure theorem in Banach spaces forthcoming in Economic Theory Bulletin

2013-19 Florian Lindner: Decision time and steps of reasoning in a competitive market entry game

2013-18 Michael Greinecker, Konrad Podczeck: Purification and independence

2013-17 Loukas Balafoutas, Rudolf Kerschbamer, Martin Kocher, Matthias Sutter: Revealed distributional preferences: Individuals vs. teams

2013-16 Simone Gobien, Björn Vollan: Playing with the social network: Social cohesion in resettled and non-resettled communities in Cambodia 
2013-15 Björn Vollan, Sebastian Prediger, Markus Frölich: Co-managing common pool resources: Do formal rules have to be adapted to traditional ecological norms?

2013-14 Björn Vollan, Yexin Zhou, Andreas Landmann, Biliang Hu, Carsten Herrmann-Pillath: Cooperation under democracy and authoritarian norms

2013-13 Florian Lindner, Matthias Sutter: Level-k reasoning and time pressure in the 11-20 money request game forthcoming in Economics Letters

2013-12 Nadja Klein, Thomas Kneib, Stefan Lang: Bayesian generalized additive models for location, scale and shape for zero-inflated and overdispersed count data

2013-11 Thomas Stöckl: Price efficiency and trading behavior in limit order markets with competing insiders forthcoming in Experimental Economics

2013-10 Sebastian Prediger, Björn Vollan, Benedikt Herrmann: Resource scarcity, spite and cooperation

2013-09 Andreas Exenberger, Simon Hartmann: How does institutional change coincide with changes in the quality of life? An exemplary case study

2013-08 E. Glenn Dutcher, Loukas Balafoutas, Florian Lindner, Dmitry Ryvkin, Matthias Sutter: Strive to be first or avoid being last: An experiment on relative performance incentives.

2013-07 Daniela Glätzle-Rützler, Matthias Sutter, Achim Zeileis: No myopic loss aversion in adolescents? An experimental note

2013-06 Conrad Kobel, Engelbert Theurl: Hospital specialisation within a DRGFramework: The Austrian case

2013-05 Martin Halla, Mario Lackner, Johann Scharler: Does the welfare state destroy the family? Evidence from OECD member countries

2013-04 Thomas Stöckl, Jürgen Huber, Michael Kirchler, Florian Lindner: Hot hand belief and gambler's fallacy in teams: Evidence from investment experiments

2013-03 Wolfgang Luhan, Johann Scharler: Monetary policy, inflation illusion and the Taylor principle: An experimental study

2013-02 Esther Blanco, Maria Claudia Lopez, James M. Walker: Tensions between the resource damage and the private benefits of appropriation in the commons 
2013-01 Jakob W. Messner, Achim Zeileis, Jochen Broecker, Georg J. Mayr: Improved probabilistic wind power forecasts with an inverse power curve transformation and censored regression

2012-27 Achim Zeileis, Nikolaus Umlauf, Friedrich Leisch: Flexible generation of e-learning exams in R: Moodle quizzes, OLAT assessments, and beyond

2012-26 Francisco Campos-Ortiz, Louis Putterman, T.K. Ahn, Loukas Balafoutas, Mongoljin Batsaikhan, Matthias Sutter: Security of property as a public good: Institutions, socio-political environment and experimental behavior in five countries

2012-25 Esther Blanco, Maria Claudia Lopez, James M. Walker: Appropriation in the commons: variations in the opportunity costs of conservation

2012-24 Edgar C. Merkle, Jinyan Fan, Achim Zeileis: Testing for measurement invariance with respect to an ordinal variable forthcoming in Psychometrika

2012-23 Lukas Schrott, Martin Gächter, Engelbert Theurl: Regional development in advanced countries: A within-country application of the Human Development Index for Austria

2012-22 Glenn Dutcher, Krista Jabs Saral: Does team telecommuting affect productivity? An experiment

2012-21 Thomas Windberger, Jesus Crespo Cuaresma, Janette Walde: Dirty floating and monetary independence in Central and Eastern Europe - The role of structural breaks

2012-20 Martin Wagner, Achim Zeileis: Heterogeneity of regional growth in the European Union

2012-19 Natalia Montinari, Antonio Nicolo, Regine Oexl: Mediocrity and induced reciprocity

2012-18 Esther Blanco, Javier Lozano: Evolutionary success and failure of wildlife conservancy programs

2012-17 Ronald Peeters, Marc Vorsatz, Markus Walzl: Beliefs and truth-telling: A laboratory experiment

2012-16 Alexander Sebald, Markus Walzl: Optimal contracts based on subjective evaluations and reciprocity

2012-15 Alexander Sebald, Markus Walzl: Subjective performance evaluations and reciprocity in principal-agent relations

2012-14 Elisabeth Christen: Time zones matter: The impact of distance and time zones on services trade 
2012-13 Elisabeth Christen, Joseph Francois, Bernard Hoekman: CGE modeling of market access in services

2012-12 Loukas Balafoutas, Nikos Nikiforakis: Norm enforcement in the city: A natural field experiment forthcoming in European Economic Review

2012-11 Dominik Erharter: Credence goods markets, distributional preferences and the role of institutions

2012-10 Nikolaus Umlauf, Daniel Adler, Thomas Kneib, Stefan Lang, Achim Zeileis: Structured additive regression models: An $\mathrm{R}$ interface to BayesX

2012-09 Achim Zeileis, Christoph Leitner, Kurt Hornik: History repeating: Spain beats Germany in the EURO 2012 Final

2012-08 Loukas Balafoutas, Glenn Dutcher, Florian Lindner, Dmitry Ryvkin: The optimal allocation of prizes in tournaments of heterogeneous agents

2012-07 Stefan Lang, Nikolaus Umlauf, Peter Wechselberger, Kenneth Harttgen, Thomas Kneib: Multilevel structured additive regression

2012-06 Elisabeth Waldmann, Thomas Kneib, Yu Ryan Yu, Stefan Lang: Bayesian semiparametric additive quantile regression

2012-05 Eric Mayer, Sebastian Rueth, Johann Scharler: Government debt, inflation dynamics and the transmission of fiscal policy shocks forthcoming in $\underline{\text { Economic Modelling }}$

2012-04 Markus Leibrecht, Johann Scharler: Government size and business cycle volatility; How important are credit constraints? forthcoming in Economica

2012-03 Uwe Dulleck, David Johnston, Rudolf Kerschbamer, Matthias Sutter: The good, the bad and the naive: Do fair prices signal good types or do they induce good behaviour?

2012-02 Martin G. Kocher, Wolfgang J. Luhan, Matthias Sutter: Testing a forgotten aspect of Akerlof's gift exchange hypothesis: Relational contracts with individual and uniform wages

2012-01 Loukas Balafoutas, Florian Lindner, Matthias Sutter: Sabotage in tournaments: Evidence from a natural experiment published in Kyklos 


\title{
University of Innsbruck
}

\section{Working Papers in Economics and Statistics}

2013-29

Tanja Hörtnagl, Rudolf Kerschbamer, Rudi Stracke, Uwe Sunde

Heterogeneity in rent-seeking contests with multiple stages: Theory and experimental evidence

\begin{abstract}
This paper investigates how heterogeneity in contestants' investment costs affects the competition intensity in a dynamic elimination contest. Theory predicts that the absolute level of investment costs has no effect on the competition intensity in homogeneous interactions. Relative cost differences in heterogeneous interactions, however, reduce equilibrium expenditures. Evidence from lab experiments for treatments with homogeneous participants is qualitatively in line with the theoretical prediction. The effect of cost differences on expenditures is positive rather than negative, however, in all heterogeneous treatments.
\end{abstract}

ISSN 1993-4378 (Print)

ISSN 1993-6885 (Online) 